Article

\title{
Fuzzy Logic Based Multi-Criteria Wind Turbine Selection Strategy-A Case Study of Qassim, Saudi Arabia
}

\author{
Shafiqur Rehman ${ }^{1}$ and Salman A. Khan ${ }^{2, *}$ \\ 1 Center for Engineering Research, Research Institute, King Fahd University of Petroleum and Minerals, \\ Dhahran 31261, Saudi Arabia; srehman@kfupm.edu.bh \\ 2 Computer Science Department, University of Pretoria, Pretoria 0002, South Africa \\ * Correspondence: skhan@cs.up.ac.za; Tel.: +27-12-420-2361 \\ Academic Editor: Frede Blaabjerg \\ Received: 20 July 2016; Accepted: 22 September 2016; Published: 26 October 2016
}

\begin{abstract}
The emergence of wind energy as a potential alternative to traditional sources of fuel has prompted notable research in recent years. One primary factor contributing to efficient utilization of wind energy from a wind farm is the type of turbines used. However, selection of a specific wind turbine type is a difficult task due to several criteria involved in the selection process. Important criteria include turbine's power rating, height of tower, energy output, rotor diameter, cut-in wind speed, and rated wind speed. The complexity of this selection process is further amplified by the presence of conflicts between the decision criteria. Therefore, a decision is desired that provides the best balance between all selection criteria. Considering the complexities involved in the decision-making process, this paper proposes a two-level decision turbine selection strategy based on fuzzy logic and multi-criteria decision-making (MCDM) approach. More specifically, the fuzzy arithmetic mean operator is used in the decision process. The proposed approach is applied to wind data collected from the site of Qassim, Saudi Arabia. Results indicate that the proposed approach was effective in finding the optimal turbine from a set of 20 turbines of various capacities.
\end{abstract}

Keywords: wind turbine; wind energy; fuzzy logic; decision-making; fuzzy arithmetic mean operator

\section{Introduction}

Renewable sources of energy such as wind, solar photovoltaic, solar thermal, geothermal, biomass, municipal waste, tides and waves, and small and large hydro are being used globally to combat the deteriorating climatic conditions, and at the same time meeting the growing demand for energy. The renewable sources of energy are independent of the location and hence can be tapped anywhere, and can provide energy to people living in remote areas which are not connected to the grid. Of these clean and freely available sources of energy, wind has been accepted commercially [1-3] due to ease of installation, operation and maintenance, and availability of advanced wind turbines of all sizes from few kilowatts to multi-megawatt. It is easy and fast to deploy wind turbines requiring minimal attention. Furthermore, these turbines have a life span of 20 to 25 years. Beside all technical and commercial advantages, wind power harnessing does not need any kind of transportation and does not have geographical boundaries [4,5].

In recent years, wind power generation has emerged as the fastest growing source of energy on global scale. A recent report from Global Wind Energy Council (GWEC) [6] states that the cumulative global wind power installed capacity reached $432,419 \mathrm{MW}$ at the end of 2015 compared to 17,400 MW in year 2000, showing an increase of about $2485.2 \%$ in a period of 16 years as depicted in Figure 1. The cumulative installed capacity increased from 369,695 MW in 2014 to 432,419 MW in 2015, which is approximately $17 \%$. China leads the global share with addition of 30,500 MW capacities 
in 2015. This was followed by the United States, Germany, Brazil, and India, which added 8598, 6013, 2754, and 2623 MW capacities, respectively. The situation in Africa and the Middle East is slow but improving, with South Africa, Ethiopia, and Jordan adding 483, 153, and 117 MW, respectively, bringing the total to $753 \mathrm{MW}$.

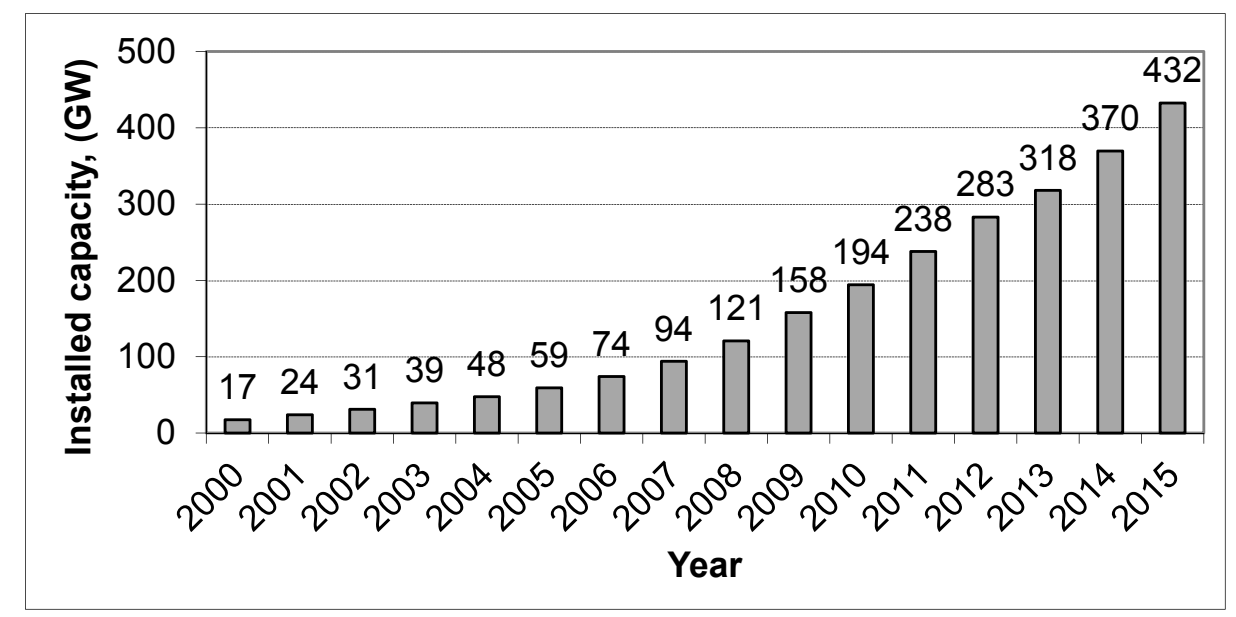

Figure 1. Global cumulative wind power installed capacities [6].

Although the wind power technology is simple and extraction of power from wind is easy, there are some challenges such as maximizing the output from the wind turbines and maintaining uninterrupted power due to intermittent and fluctuating nature of the wind. The wind speed is highly site dependent, and changes with time of the day, day of the year, height above ground level (AGL), and topography. Usually, the wind speed measurements are made at 8 to $12 \mathrm{~m} \mathrm{AGL,} \mathrm{whereas} \mathrm{the} \mathrm{hub}$ heights of the modern wind turbines of multi megawatt capacities vary from 80 to $120 \mathrm{~m}$. Hub height refers to the height of the tower at which the turbine rotor is installed to harness the wind which can then be converted to energy. The hub height cannot exceed a threshold value due to technical, installation, economical, and maintenance issues. Hence, it is important to have an accurate knowledge of the suitable hub height for a particular location and for a particular type of wind turbine for maximum energy output from wind turbines [6].

In general, as the wind speed increases with height, the energy output from the turbine also increases. Therefore, for increased wind energy output from a selected wind turbine, the hub height should be as high as possible, both economically and technology wise. However, the hub height cannot be increased randomly. This implies that the two decision criteria of hub height and energy output are conflicting in nature, and it is not possible to optimize both criteria at the same time. In addition to these factors, other factors specific to the turbine such as rotor diameter, cut-in wind speed and rated wind speed contribute to the energy extraction. However, many of the aforementioned factors are conflicting with each other: improving one factor negatively affects the others. Moreover, there is no direct or indirect proportional relationship between some of these factors, which further adds to difficulty in choosing a suitable turbine. For example, some turbines have bigger rotor diameters, which is desired due to larger swept area and hence more power. Wind turbines with low cut-in and rated wind speeds are required for higher wind energy productions and are more suitable at low windy sites.

A possible approach to select the best turbine in presence of aforementioned conflicting factors is to opt for a solution that would provide an optimal balance between the all factors (also termed as decision criteria). An approach following this rationale was proposed in various studies $[4,7,8]$, which was based on multi-criteria decision-making (MCDM) and utilized fuzzy logic to find the best balance between two criteria, i.e., hub height and rated power output/zero power output. The underlying fuzzy function to reach the decision was based on the Unified And-Or (UAO) operator [9] or Werners' 
operator [10]. However, one potential drawback of the aforementioned operators is that the results are sensitive to the value of an operator-related parameter, and a minor change in the value of this parameter could reflect significant variations in the final decision. Similar concerns are associated with various other well-known operators such as Dombi's operator [11,12], Hamacher's operator [13], Frank's operator [14], Weber's operators [15], Dubois and Prade's operator [16], and Schweizer's operator [17], among many others. However, there is one fuzzy operator that does not contain any operator-related parameter, and therefore does not suffer from the issues that arise with fuzzy operators mentioned above. This operator is known as fuzzy arithmetic mean operator [18] and has been used in a number of MCDM problems. The fuzzy arithmetic mean operator provides motivation for its utilization for finding the best trade-off between the various relevant factors, which serves as the core of the proposed work to select the optimal turbine type for the underlying wind farm site.

The rest of this paper is organized as follows. Section 2 provides the current status of wind turbine selection problem. Contributions and novel aspects of the proposed approach are discussed in Section 3. Section 4 provides the discussion on the research method. In Section 5, discussion is provided as how fuzzy logic is applied to the underlying problem. The results and discussion are provided in Section 6. Finally, the paper concludes in Section 7.

\section{Current Status of Wind Turbine Selection Problem}

Efficient and effective wind farm development depends on various important factors. These factors may include the selection of potential windy site for the wind farm development, wind farm layout design, and selection of efficient wind turbines that would result in maximum power generation. Installation of a wind turbine involves the transportation of large and heavy turbine components to the site, laying the foundation and building the high towers, provision of appropriate and highly skilled installation crew, maintenance, and various other engineering challenges. The overall issue in this process is to minimize the total financial project cost. The cost of tower is an important element, contributing substantially to the overall cost. An increase by only $10 \mathrm{~m}$ in the hub height results in cost increment in the range of $6 \%$ to $16 \%$, with an average increase of $10.33 \%$ [7]. Thus, it is important to optimize this cost, which in turn requires that the hub height be kept optimal.

In contrast to the above requirement, a wind farm operator demands maximum possible energy output from the wind farm. However, the annual energy output is adversely affected by unavailability, electrical and wake effect losses, zero output percentage (ZOP) and rated output percentage (ROP). Mean net energy output is defined as the energy available to the grid after taking in to consideration the various losses mentioned above. This energy output needs to be optimized while dealing with all prevailing favorable or unfavorable conditions.

As mentioned above, an efficient wind farm design depends on several major factors such as the selection of proper site, wind farm layout, and selection of appropriate wind turbines. Each of these factors is treated as a complex optimization and decision-making problem $[19,20]$. The complexity of these problems is further amplified by several other aspects [20], such as environmental, technical, and setback constraints. Since the focus of this study is on wind turbine selection and MCDM techniques, the literature review is divided into two parts. The first part is concerned with the use of MCDM techniques on the first two aspects, namely, site selection and layout optimization. The second part focuses on the turbine selection problem and evaluates different strategies adopted for the purpose, including the multi-criteria approaches.

\subsection{Multi-Criteria Decision-Making Techniques for Site Selection and Layout Design}

Due to the complexity of the aforementioned problems, substantial attention has been given in recent years to the use of computational intelligence $(\mathrm{CI})$ techniques for dealing with these problems in a more systematic and efficient way. The problems can either be treated as single-criteria or multi-criteria. It has been shown [21] that these problems should better be solved as multi-criteria (also referred to as multi-objective) problems as it is a more logical and naturalistic approach to deal with these problems 
and can result in better solutions. It is due to this fact that many researchers working in the field of wind farm design have resorted to the use of multi-criteria optimization and decision-making techniques. The primary motivation for the use of CI techniques is to develop automated decision-making techniques that are not only efficient, but replace the human-based decision making which are prone to inefficient, and rather wrong decisions. A variety of CI based MCDM techniques such as weighted aggregation [22], Pareto ranking [23], and fuzzy logic [24] have been employed by researchers in various sub-domains of wind farm design. For example, wind farm site selection problem has been treated as a MCDM problem in various studies. Some recent studies in this direction used weighted aggregation [25-28], fuzzy logic [29-32], and Pareto ranking [33]. A more comprehensive coverage of other relevant studies is given in a recent survey by Herbert-Acero et al. [19]. As far as wind farm layout is concerned, many studies have utilized the aforementioned multi-criteria approaches. Use of weighted aggregation has been reported in various studies [34-37], whereas Pareto ranking has also been used in a number of research works [38-42]. In addition, a comprehensive literature review covering various aspects of wind farm design has been reported in various research articles $[19,21,43,44]$.

\subsection{Approaches for Turbine Selection Problem}

Considerable attention has also been given to the turbine type selection. Sarja and Halonen [45] performed a research with semi-structured interviews conducted with domain experts and identified several selection criteria such as product reliability, production volume, cost factors, availability factors, and the organization of maintenance. Based on the outcome of the interviews, selection criteria were ordered based on their importance. However, as stated in their article, it was not possible to form a detailed and prioritized list of selection criteria, but still some general themes emerged. The main limitation of their study was that it did not provide a mathematical model that would quantify the results which could facilitate the decision-making process. Perkin et al. [46] identified five selection criteria, namely, the diameter of rotor, generator size, hub height, pitch angle range, and rotations per minute (RPM) range. These criteria were embedded into the chromosome encoding of a genetic algorithm that was used to obtain the best turbine. This was an interesting approach, but was computationally expensive due to the use of genetic algorithm. Nemes and Munteanu [47] presented an approach based on system reliability indices which was used to compare nine different wind turbine types. Chowdhury et al. [48] carried out wind turbine selection based on a single criterion, energy production capacity, and particle swarm optimization algorithm was used as the underlying optimization algorithm. Furthermore, a single wind turbine type was assumed. Similar to the case of Perkin et al. [46], the concern in this situation was algorithmic and computational complexities associated with particle swarm optimization, along with the accuracy of the decision process due to a single criterion. Firuzabad and Dobakhshari [49] used a probabilistic model based on turbine reliability to select the turbine assuming five turbine types. The main limitation here was also that only a single-objective was considered in the decision process. Bencherif et al. [50] considered capacity factor as the decision criteria considering 24 turbine types. An analytical approach based on Weibull distribution was adopted for selection. Montoya et al. [51] proposed Pareto ranking-based genetic algorithms to get the best turbines considering power output and deviation in daily power output as the decision criteria. Chowdhury et al. [52] assumed optimization of cost of energy as the turbine selection criterion, while assuming 121 different turbine types. However, one issue with their proposed selection approach was its computational complexity.

Martin et al. [53] optimized the rotor-to-generator ratio for a hypothetical wind turbine using a range of wind conditions. However, it was stated that the approach can only serve as a support tool, rather than a complete selection method since many other important factors involved in the turbine selection process were not considered in the research. Bekele and Ramayya [54] proposed a site specific design for wind turbine considering blade design as the optimization factor. A genetic algorithm was used to optimize the blade shape. One potential drawback of this approach was that it 
did not use off-the-shelf turbines, making the approach totally site specific. Helgason [55] conducted a study on several potential sites in Iceland using 47 different turbines. One optimization criterion, namely, minimum cost of energy was considered which was modeled as function of expected annual energy output, capacity factor, and cost of energy. Eke and Onyewudiala [56] had similar issues where the approach was to design a site specific turbine assuming shape parameters comprising the chord, the twist and the relative thickness of the blade. The idea was to modify these parameters of two existing turbines so that the modified design could generate more power. Genetic algorithm was used but it was not discussed as how the three decision factors were used in the optimization process. Jureczko et al. [57] proposed an approach based on genetic algorithm for turbine design considering blade vibrations, output generated, blade material cost, stability of blade structure, and strength requirements by the blade structure as the design parameters.

Jowder [58] proposed a selection approach that used capacity factor as the decision variable for a site in Bahrain. Furthermore, only six commercially available turbines were considered in the study. El-Shimy [59] proposed a site-specific turbine selection approach while considering capacity factor, normalized average power output, and turbine-performance-index. One drawback of the approach was its complexity and subjectivity in the sense that the results required in-depth interpretations by a domain expert and the interpretations could vary from person to person. Abul'Wafa [60] proposed a method of matching wind turbine generators to a site using turbine performance index (TPI) in conjunction with minimum deviation ratio (DR) between rated speed of wind turbine generator (WTG) and optimal speed and resulting in minimum cost of energy. Although the paper claims that twenty-five potential turbines were assessed, results and analysis of only a few turbines were given in the article. Dong et al. [61] proposed three criteria, namely matching index, turbine cost index and the integrated matching index for turbine selection. Three optimization algorithms were used which were particle swarm optimization, differential evolution, and genetic algorithm.

The most relevant study to the work proposed herein was by Shirgholami et al. [62] who identified more than 30 decision criteria as used in the literature. However, it was also identified that only a subset of the given criteria can be used under specific conditions. In their work, Shirgholami et al. used 11 decision factors which included capacity factor, availability, rotor efficiency, life time costs, initial capital costs, operating and maintenance costs, environmental issues, impact on wildlife, noise emission, visual impact, supplier performance, satisfaction level delivery, and political stability. Furthermore, only four wind turbine types were considered in the study. An Analytic Hierarchy Process (AHP) based approach [22] was used for the decision making process. Another similar study was done by Bagočius et al. [63] who proposed a turbine selection strategy for offshore wind farms. They used the WASPAS method, which is similar to the AHP approach. Five criteria, namely, nominal power of the wind turbine, max power generated in the area, the amount of energy per year generated in the area, investments, and $\mathrm{CO}_{2}$ emissions were taken into consideration. Furthermore, only four turbine types were considered for assessment.

Lee et al. [64] presented a multi-criteria decision approach considering four major decision criteria namely machine characteristics, economic aspects, environmental issues and technical challenges. However, one major limitation of their study was that it was focused on rating the mutual importance of the four decision criteria, without showing the actual implementation of how this was applied to real turbine data. Since there were some very technical sub-criterion involved in the decision process, actual data for this sub-criterion was almost impossible to obtain from open sources or vendors, thus making the approach less practical. They assumed only four turbines of almost same rated power in their study.

Khan and Rehman $[7,8]$ were the first in reporting the use of fuzzy logic based MCDM for turbine selection problem. However, the approach proposed therein had some limitations. For example, only three criteria were considered in the decision making process. In addition, the study in each paper was focused on a specific rated output range, limiting the variety of turbine types studied. Furthermore, as discussed in Section 1, the fuzzy operators used in those studies were less effective compared to the fuzzy operator used in the current study. 


\section{Novelty and Contribution of the Proposed Approach}

From above literature review, the following limitations are observed.

(1) Simple decision models. Majority of reviewed research $[47-50,52-55,58]$ has been limited to using one decision criterion for the turbine selection process, which introduces limitations in the decision process.

(2) Decision parameters that cannot be known by the developer. Most research papers assumed decision parameters for which information is not easily accessible (i.e., blade shape, product reliability, production volume, availability factors, organization of maintenance, system reliability indices, environmental issues, visual impact, political stability, among many others) [45-49,53-63]. Such parameters result in the selection approach being very complex and impractical.

(3) Restriction to a small variety of turbine types. Many research papers [47-49,53,54,56,58,62-64] have used a small set of turbines type despite a huge variety of commercially available turbines.

(4) Slow/inefficient optimization techniques (i.e., brute force calculations or iterative heuristics). Optimization techniques such as genetic algorithms, particle swarm optimization, non-linear programming, and other complex approaches are computationally less efficient. Despite this, such approaches have been frequently used in the turbine selection problems $[46,48-57,59-61,64]$.

(5) Failure to account for impact of changing hub height on cost and production. This important aspect has also been ignored in a number of studies $[47-49,53,57,62]$.

(6) Conflict and incommensurability of criteria. While a number of studies [45,46,51,55-57,59-62,64] have assumed multiple criteria for selection of the best turbine type, all of them have missed the two fundamental aspects of MCDM. These aspects are known as conflict between criteria and incommensurability. Note that the aim of MCDM is to make decision on finding the best solution from a pool of available alternatives. These decisions generally involve high degree of complexity since a number of conflicting criteria are involved in the decision making process. Conflict between criteria occurs when improvement in one (or more) criterion/criteria results in degradation in other criteria. Incommensurability refers to the decision criteria being in different units and magnitudes. The studies have not discussed (or even considered) these two aspects in proposing the turbine selection problem.

With the above observations, the contribution of this work lies in addressing the above issues and proposing a novel and simple turbine selection approach. The proposed approach would provide a decision model consisting of six important, yet simple decision criteria. These criteria can be easily obtained for any commercially available turbine, thus reducing the total time of the selection process. Furthermore, as opposed to computationally inefficient techniques, the proposed fuzzy logic based approach produces solutions in linear time. In addition, 20 turbines of different rated outputs and different vendors have been used, thus providing a variety in the selection process. The proposed fuzzy logic approach also inherently addresses the conflict and incommensurability issues.

It is also worth mentioning that the proposed approach is robust and scalable, as opposed to previous studies. That is, any number of criteria can be added or removed as per the designer's requirements, and any degree of mutual preference can be introduced among the criteria.

\section{Research Method}

The research follows a quantitative model and is based on an experimental study. From the literature survey, the important decision criteria have been identified. Based on these criteria, a two-level fuzzy logic model has been developed. Six decision criteria were considered in the model. These criteria include hub height, wind speed, mean net energy output, rotor diameter, cut-in wind speed, and rated wind-speed. The measurements were taken with a step size of $5 \mathrm{~m}$ for hub height. In order to develop the two-level fuzzy logic model for the underlying problem, the upper and lower 
limits for each decision criteria were found using the data collected for the concerned site. Using these bounds and the data from the sites, fuzzy membership values for each criterion are computed and aggregated in form of an overall decision function according to the proposed approach.

The above approach was implemented as a computational program in C++. The program takes the site specific data as input and generates several solutions. The best (optimal) solution is also identified by the program based on the strategy discussed in Section 5 . The site specific information focuses on data for wind turbines in the range of 600-2000 kW. Empirical analysis was performed, providing comparisons of different types of turbines for the site. Based on the outcomes of the analysis, interpretations and recommendations were made.

\section{Application of Fuzzy Logic to Wind Turbine Selection}

MCDM is a technique used in situations requiring decisions while considering multiple and "conflicting" decision criteria. Conflicting criteria are those criteria which negatively impact each other, i.e., improving the quality of one criterion degrades the quality of other(s). A fundamental requirement pertaining to the application of fuzzy logic to MCDM problems is that the criteria be aggregated to form an overall decision function, which is a scalar value. However, this raises the concern of "incommensurability" of criteria, a scenario arising due to the different units and magnitudes of the criteria. Due to incommensurability, different criteria cannot be aggregated into one decision function, and therefore it is essential to bring all criteria to a uniform, unit-less scale. Fuzzy logic [24] has been effectively used for decades to solve a number of MCDM problems involving the aforementioned issues [65-75].

The fuzzy logic approach proposed in this work is a two-level strategy. In the first level, fuzzy arithmetic mean operator is applied to three selection criteria which are hub height, wind speed, and mean energy output. In order to apply fuzzy arithmetic mean operator to this level, all three criteria need to be fuzzified to overcome the incommensurability issues. This is achieved through finding the membership functions for the three criteria. In the second level, the results of the first level are combined with additional criteria to find the best turbine among all turbines. Again, these additional criteria are first fuzzified and then aggregated with the results of the first level. The criteria for the second level include rotor diameter, cut-in wind speed, and rated wind speed.

\subsection{Calculation of Membership Function}

The achievement level of each criterion is evaluated through a membership function. Thus, a membership function should be defined for each criterion individually. The membership function takes a value that ranges from 0 to 1 to express the achieved satisfaction level. While the value of 0 indicates total dissatisfaction, the value of 1 indicates complete satisfaction. Several membership functions can be defined that differ in mathematical structure [76]. The structure of a membership function determines the penalization pattern of undesired deviation.

\subsection{Application of Fuzzy Logic to the First Level}

In order to utilize fuzzy logic for level one, three linguistic variables, namely, "Hub Height", "Wind speed", and "Mean Net Energy Output" are defined. Note that our interest is in the terms "low hub height", "low wind speed" and "high mean net energy output". It should be noted that there is no linear relationship among these parameters. Wind speed is exponentially dependent on height ratio and the wind shear exponent. The wind power density is directly proportional to the cube of mean wind speed and hence the mean energy output. In addition, note that the three variables (i.e., criteria) are mutually conflicting, since higher hub heights (which are not desired) will ideally give high energy output (desirable) at high wind speed (undesirable). Thus, improvement in energy output would mean higher hub heights and higher wind speeds. Accordingly, an optimal ratio is desired such the best balance between the hub height, wind speed, and energy output is achieved. This can be achieved by defining the following rule. 
Rule 1: IF a solution $X$ has low hub height AND low wind speed AND high mean net energy output THEN it is a good solution.

In the above rule, $X$ refers to a solution (i.e., a ratio) that results due to the combined effect of certain value of hub height and its corresponding wind speed and energy output. The terms "low hub height", "low wind speed", "high mean net energy output", and "good solution" are linguistic values, each of which defines a fuzzy subset of solutions. Each fuzzy subset is defined by a membership function, $\mu(x)$. The membership function returns a value in the interval $[0,1]$, describing the degree of satisfaction with the decision criterion under consideration. This process converts the crisp values of three decision criteria into a [0,1] range, and without any units.

The membership functions for the three criteria at the first level are determined as follows.

\subsubsection{Membership Function for Hub Height}

The membership function for the hub height is formed by determining two extreme values (upper and lower bounds) for hub height. The two limits (i.e., the minimum hub height, HMin, and maximum hub height, HMax) are found based on the technical specifications of the turbines, as will be discussed in Section 5. The membership function for the hub height, $\mu_{\mathrm{H}}(x)$, is mathematically represented as follows.

$$
\mu_{\mathrm{H}}(x)=\left\{\begin{array}{cl}
1 & \text { if Height }(x) \leq \text { HMin } \\
\frac{\text { HMax }- \text { Height }(x)}{\text { HMax }- \text { HMin }} & \text { if HMin }<\text { Height }(x) \leq \text { HMax } \\
0 & \text { if Height }(x)>\text { HMax }
\end{array}\right.
$$

\subsubsection{Membership Function for Wind Speed}

The membership function for the wind speed is defined in a manner similar to that of hub height. The upper and lower bounds for wind speed are determined. The lower bound, SMin, as well as the upper bound, SMax, are found based on the collected data (as explained in Section 5). Equation (2) represents the membership function, $\mu_{S}(x)$, for the wind speed.

$$
\mu_{\mathrm{S}}(x)=\left\{\begin{array}{cl}
1 & \text { if Speed }(x) \leq \text { SMin } \\
\frac{\text { SMax }- \text { Speed }(x)}{\text { SMax-SMin }} & \text { if SMin }<\text { Speed }(x) \leq \text { SMax } \\
0 & \text { if Speed }(x)>\text { SMax }
\end{array}\right.
$$

\subsubsection{Membership Function for Mean Net Energy Output}

Finally, the membership function for mean net energy output can be formed as follows. The two bounds for energy output are determined first, using the collected data. Equation (3) represents the membership function, $\mu_{\mathrm{E}}(x)$, for mean net energy output. In this equation, EMax and EMin correspond to the upper and lower bounds, respectively.

$$
\mu_{\mathrm{E}}(x)=\left\{\begin{array}{cl}
1 & \text { if Energy }(x) \geq \text { EMax } \\
\frac{\operatorname{Energy}(x)-\text { EMin }}{\text { EMax }- \text { EMin }} & \text { if EMin } \leq \text { Energy }(x)<\text { EMax } \\
0 & \text { if Energy }(x)<\text { EMin }
\end{array}\right.
$$

\subsubsection{Calculation of the Overall Membership Function at Level 1}

The next step is to aggregate all individual memberships for the three criteria. This is done using Rule 1, which is mathematically represented by fuzzy arithmetic mean operator. The operator places all membership functions into a single aggregation function that measures the degree of satisfaction of 
the overall membership function. The mathematical representation of overall membership function for solution $x, O M(x)$, is given in the following equation.

$$
O M(x)=\frac{\alpha_{1} \mu_{\mathrm{H}}(x)+\alpha_{2} \mu_{\mathrm{S}}(x)+\alpha_{3} \mu_{\mathrm{E}}(x)}{3}
$$

In Equation (4) above, $O M(x)$ represents the overall membership of the three criteria collectively. Furthermore, the coefficients $\alpha_{1}, \alpha_{2}$, and $\alpha_{3}$ are weights used to indicate the priority of a specific design objective. In this work, a general problem is considered that gives equal consideration to all design objectives. The solution that results in the maximum value for Equation (4) is reported as the best solution found.

Let us take an example to see how the method works at the first level.

Example 1. Assume the data for Fuhrlder FL 600 in Table A1. We will take the data in the first two rows to illustrate how the approach works. The data in the two rows are as follows.

Row 1: Hub height $=50 \mathrm{~m}$, Wind Speed $=4.51 \mathrm{~m} / \mathrm{s}$, and Mean Net Energy Output $=652,928 \mathrm{kWh} /$ year

Row 2: Hub height $=55 \mathrm{~m}$, Wind Speed $=4.63 \mathrm{~m} / \mathrm{s}$, and Mean Net Energy Output $=706,370 \mathrm{kWh} /$ year

In order to calculate the memberships, Equations (1)-(3) should be used appropriately along with the upper and lower limits for each criterion (the upper and lower limits are given in Table 1.

From Equation (1), membership values for hub height in Row $1=0.778$ and Row $2=0.772$

From Equation (2), membership values for wind speed in Row $1=0.255$ and Row $2=0.307$

From Equation (3), membership values for energy output in Row $1=0.307$ and Row $2=0.337$

From Equation (4), the overall membership $(O M)$ for Row $1=(0.778+0.255+0.307) / 3=0.447$

Again from Equation (4), OM for Row $2=(0.772+0.307+0.337) / 3=0.458$

As per the rules of fuzzy logic, since Row 2 has higher OM value than Row 1, data in Row 2 is a better choice than that of Row 1 . Note that the approach is done to select the best combination of hub height, wind speed, and energy output for the same turbine. The procedure has to be repeated separately for each turbine as done in Tables A1-A20.

Table 1. Upper and lower bounds for level 1.

\begin{tabular}{ccccccccc}
\hline \multirow{2}{*}{$\begin{array}{c}\text { Turbine Rated } \\
\text { Power Range (kW) }\end{array}$} & \multicolumn{2}{c}{ Hub Height $\mathbf{( m )}$} & & \multicolumn{2}{c}{ Wind Speed $(\mathbf{m} / \mathbf{s})$} & & \multicolumn{2}{c}{ Energy Output (kWh/Year) } \\
\cline { 2 - 3 } & Lower & Upper & & Lower & Upper & & Lower & Upper \\
\hline $500-750$ & 30 & 120 & & 4 & 6 & & 100,000 & $1,900,000$ \\
$1000-1250$ & 30 & 120 & & 4 & 6 & & 500,000 & $2,200,000$ \\
2000 & 30 & 120 & & 4 & 6 & & $1,000,000$ & $4,900,000$ \\
\hline
\end{tabular}

\subsection{Application of Fuzzy Logic to the Second Level}

The outcome of the first level identifies the most appropriate combination with respect to hub height, wind speed, and mean net energy output for each turbine. However, as mentioned earlier in Section 1, these three criteria are suitable for selecting a turbine from the same class of turbines with regard to the rated power output, but not adequate for selecting the best overall turbine in all three categories. It is due to the fact that there are three categories of turbines $(500-750 \mathrm{~kW}$, $1000-1250 \mathrm{~kW}$, and $2000 \mathrm{~kW}$ ) considered herein and each category has its own suitable hub height range, suitable wind speed range, and most importantly, mean net energy output. Therefore, more criteria are needed to appropriately consider the effect of difference in rated energy output of different turbines. This motivated the need for a second level of decision making, thus prompting the application of fuzzy arithmetic mean operator also to the second level while considering rotor diameter, cut-in wind speed, and rated wind-speed as the decision criteria. The approach follows the same methodology adopted 
at the first level. This requires defining a second rule for the second level, finding the membership function for the three criteria, and aggregate them along with the overall membership of level 1 through fuzzy arithmetic mean operator.

Rule 2: IF a solution $X$ has big rotor diameter AND low cut-in wind speed AND low rated wind speed AND high overall membership at level 1 THEN it is a good solution.

In order to utilize fuzzy logic for level 2, again three linguistic variables, namely, "Rotor diameter", "Cut-in wind speed", and "Rated wind-speed" are defined. The next step is to define three membership functions for the criteria at level 2, which is done as explained below.

\subsubsection{Membership Function for Rotor Diameter}

The development of membership function for rotor diameter requires the upper and lower bounds to be defined. Tables 2-4 indicate that the rotor diameter for all turbines varies between 33 and $93 \mathrm{~m}$. Note that higher rotor diameter is desired since this allows more absorption of wind power. The upper limit, DMax, is taken as $95 \mathrm{~m}$ while the lower limit, DMin, is assumed to be $30 \mathrm{~m}$. The membership function for the rotor diameter, $\mu_{D}(x)$, is represented as follows.

$$
\mu_{\mathrm{D}}(x)=\left\{\begin{array}{cl}
1 & \text { if Diameter }(x) \geq \text { DMax } \\
\frac{\text { Diameter }(x)-\text { DMin }}{\text { DMax }- \text { DMin }} & \text { if DMin } \leq \text { Diameter }(x)<\text { DMax } \\
0 & \text { if Diameter }(x)<\text { DMin }
\end{array}\right.
$$

Table 2. Technical specifications of the wind turbines in the range of 500-750 kW.

\begin{tabular}{cccccc}
\hline Turbine & $\begin{array}{c}\text { Minimum Hub } \\
\text { Height } \mathbf{( m )}\end{array}$ & $\begin{array}{c}\text { Rotor } \\
\text { Diameter }(\mathbf{m})\end{array}$ & $\begin{array}{c}\text { Cut-in Wind } \\
\text { Speed }(\mathbf{m} / \mathbf{s})\end{array}$ & $\begin{array}{c}\text { Rated Wind } \\
\text { Speed } \mathbf{( m / s )}\end{array}$ & $\begin{array}{c}\text { Rated Power } \\
\mathbf{( k W )}\end{array}$ \\
\hline Fuhrlder FL 600 & 50 & 50 & 2.5 & 11 & 600 \\
Hyosung HS50 & 50 & 50 & 3.5 & 11 & 750 \\
RRB Energy PS 600 & 48 & 47 & 3.5 & 15 & 600 \\
Suzlon S.52/600 & 75 & 52 & 4 & 13 & 600 \\
Unison U57 & 68 & 57 & 3 & 10.5 & 750 \\
Vestas V47 & 55 & 47 & 4 & 13 & 660 \\
Windflow 500 & 29 & 33 & 6 & 14 & 500 \\
\hline
\end{tabular}

Table 3. Technical specifications of the wind turbines in the range of 1000-1250 kW.

\begin{tabular}{cccccc}
\hline Turbine & $\begin{array}{c}\text { Minimum Hub } \\
\text { Height }(\mathbf{m})\end{array}$ & $\begin{array}{c}\text { Rotor } \\
\text { Diameter }(\mathbf{m})\end{array}$ & $\begin{array}{c}\text { Cut-in Wind } \\
\text { Speed } \mathbf{( m / s )}\end{array}$ & $\begin{array}{c}\text { Rated Wind } \\
\text { Speed }(\mathbf{m} / \mathbf{s})\end{array}$ & $\begin{array}{c}\text { Rated Power } \\
\mathbf{( k W )}\end{array}$ \\
\hline AAER A-1000 & 70 & 58 & 4 & 12 & 1000 \\
DeWind D6 64m & 60 & 64 & 2.5 & 12.3 & 1250 \\
Mitsubishi MWT62 & 69 & 61.4 & 3.5 & 12.5 & 1000 \\
Nordex N54/1000 & 60 & 54 & 3.75 & 14 & 1000 \\
Suzlon S.62/1000 & 65 & 62 & 3 & 12 & 1000 \\
Vensys 62-1200 & 69 & 62 & 2.5 & 11.5 & 1200 \\
\hline
\end{tabular}


Table 4. Technical specifications of the wind turbines with rated power of $2000 \mathrm{~kW}$.

\begin{tabular}{cccccc}
\hline Turbine & $\begin{array}{c}\text { Minimum Hub } \\
\text { Height }(\mathbf{m})\end{array}$ & $\begin{array}{c}\text { Rotor } \\
\text { Diameter }(\mathbf{m})\end{array}$ & $\begin{array}{c}\text { Cut-in Wind } \\
\text { Speed } \mathbf{( m / s})\end{array}$ & $\begin{array}{c}\text { Rated Wind } \\
\text { Speed } \mathbf{( m / s )}\end{array}$ & $\begin{array}{c}\text { Rated Power } \\
\mathbf{( k W )}\end{array}$ \\
\hline AAER A-2000-84 & 65 & 84 & 3.25 & 12 & 2000 \\
DeWind D8.1 & 80 & 80 & 3 & 13.5 & 2000 \\
Ecotecnia 80/2000 & 70 & 80 & 3 & 12 & 2000 \\
REpower MM92 & 79 & 92 & 3 & 12.5 & 2000 \\
Suzlon S.88/2000 & 80 & 88 & 4 & 14 & 2000 \\
Unison U93 & 80 & 93 & 3 & 11 & 2000 \\
Vestas V90 & 80 & 90 & 4 & 12 & 2000 \\
\hline
\end{tabular}

\subsubsection{Membership Function for Cut-in Wind Speed}

In order to define the membership function for cut-in wind speed, the two extreme values are determined first. It is observed from Tables 2-4 that the cut-in wind speed of turbines varies from 2.5 to $6 \mathrm{~m} / \mathrm{s}$. Therefore, the upper bound, CMax, is taken as $7 \mathrm{~m} / \mathrm{s}$ while the lower bound, CMin, is taken as $2 \mathrm{~m} / \mathrm{s}$. The membership function for the cut-in wind speed, $\mu_{\mathrm{C}}(x)$, is represented by Equation (6).

$$
\mu_{C}(x)=\left\{\begin{array}{cl}
1 & \text { if CutIn Speed }(x) \leq \text { CMin } \\
\frac{\text { CMax }- \text { CutIn Speed }(x)}{\text { CMax }- \text { CMin }} & \text { if CMin <CutIn Speed }(x) \leq \text { CMax } \\
0 & \text { if CutIn Speed }(x)>\text { CMax }
\end{array}\right.
$$

\subsubsection{Membership Function for Rated Wind Speed}

The membership function for the rated wind speed is determined using the upper and lower bounds of rated wind speeds of all turbines. The values are taken from the data in Column 5 of Tables 2-4. Since the rated wind speed varies between 15 and $10.5 \mathrm{~m} / \mathrm{s}$, the upper limit, RMax, is taken as $16 \mathrm{~m} / \mathrm{s}$ while the lower limit, RMin, is taken as $10 \mathrm{~m} / \mathrm{s}$. Mathematically, the membership function for rated wind speed, $\mu_{\mathrm{R}}(x)$, is represented as follows:

$$
\mu_{\mathrm{R}}(x)=\left\{\begin{array}{cl}
1 & \text { if Rated Speed }(x) \leq \text { RMin } \\
\frac{\text { RMax }- \text { Rated Speed }(x)}{\text { RMax }- \text { RMin }} & \text { if RMin }<\text { Rated Speed }(x) \leq \text { RMax } \\
0 & \text { if Rated Speed }(x)>\text { RMax }
\end{array}\right.
$$

\subsubsection{Calculation of the Total Membership Function}

After the individual memberships at the second level are found, the next step is to aggregate all memberships as well as the overall membership from the first level, using Rule 2. Similar to level 1, this is done using the fuzzy arithmetic mean operator. The resulting mathematical expression is as given below.

$$
T M(x)=\frac{\beta_{1} \mu_{D}(x)+\beta_{2} \mu_{C}(x)+\beta_{3} \mu_{R}(x)+\beta_{4} O M(x)}{4}
$$

In Equation (8), TM $(x)$ signifies the aggregated memberships of all three objectives at the second level and overall membership from level 1. Moreover, the coefficients $\beta_{1}, \beta_{2}, \beta_{3}$ and $\beta_{4}$ are the weights that can be used to indicate the priority of a specific criterion. The solution which results in the maximum value for Equation (8) is recorded as the best solution found.

Let us now understand through an example as how the method works at the second level.

Example 2. Following the approach described in Example 1, let us assume that the best combination for each turbine type has been found (i.e., taking the best combination from each table in Appendix A). Then, the desire is to find the best overall turbine using the data for level 2 and the best result for level 1. As an example, 
assume that we want to compare any two turbines, say Unison U93 and Vestas V90. From Table 5 we observe the following data:

For Unison U93: Diameter $=93 \mathrm{~m}$, Cut-in wind speed $=3 \mathrm{~m} / \mathrm{s}$, Rated win speed $=11 \mathrm{~m} / \mathrm{s}$

For Vestas V90: Diameter $=90 \mathrm{~m}$, Cut-in wind speed $=4 \mathrm{~m} / \mathrm{s}$, Rated win speed $=12 \mathrm{~m} / \mathrm{s}$

From Level 1, OM for Unison U93 = 0.543

From Level 1, OM for Vestas V90 = 0.577

To calculate the memberships, Equations (5)-(7) should be used appropriately as discussed above.

From Equation (5), membership for Diameter for Unison U93 $=0.97$ and Vestas V90 $=0.92$

From Equation (6), membership for Cut-in wind speed for Unison U93 =0.8 and Vestas V90 =0.6

From Equation (7), membership for Rated wind speed for Unison U93 =0.83 and Vestas V90 $=0.67$

From Equation (8), while assuming equal preference for all criteria, the total membership (TM) for Unison U93 $=(0.97+0.8+0.83+0.543) / 4=0.786$

Again from Equation (8), with equal preference for criteria, TM for Vestas V90 $=(0.92+0.6+0.67+0.577) / 4$ $=0.692$

Since Unison U93 has higher membership value than Vestas V90 (i.e., 0.786 vs. 0.692), we conclude that Unison U93 is a better choice than Vestas V90 for the given site.

Table 5. $\mathrm{TM}$ for all turbines. $\mathrm{OM}=$ overall membership and $\mathrm{TM}=$ total membership.

\begin{tabular}{cccccccc}
\hline Turbine & $\begin{array}{c}\text { Diameter } \\
(\mathbf{m})\end{array}$ & $\begin{array}{c}\text { Cut-in Wind } \\
\text { speed }(\mathbf{m} / \mathbf{s})\end{array}$ & $\begin{array}{c}\text { Rated Wind } \\
\text { speed (m/s) }\end{array}$ & OM & $\begin{array}{c}\text { Membership } \\
\text { Diameter }\end{array}$ & $\begin{array}{c}\text { Membership } \\
\text { Cut-in Speed }\end{array}$ & $\begin{array}{c}\text { Membership } \\
\text { Rated Speed }\end{array}$ \\
\hline Unison & 93 & 3 & 11 & 0.543 & 0.97 & 0.8 & 0.83 \\
U93 & 90 & 4 & 12 & 0.577 & 0.92 & 0.6 & 0.67 \\
\hline Vestas V90 & 90 & 4 & & & \\
\hline
\end{tabular}

\section{Results and Discussion}

The study was performed on a potential experimental site of Qassim located in the central part of Saudi Arabia. The location has an altitude of $648 \mathrm{~m}$ above sea level. As discussed in Section 4 the simulator executes the MCDM calculations with the input data, and generates the output decision based on the two-level fuzzy logic approach described in Sections 5.2 and 5.3. With respect to first level of decision, for each set of data associated with a specific turbine, the value which generated the highest membership according to Rule 1 was chosen as the best solution (representing the best balance between the three decision criteria). Twenty different turbine types, with different rated powers were assumed. Of these, seven turbines were having rated power output in the range of $500-750 \mathrm{~kW}$, six turbines were in the range of 1000-1250 kW, and the remaining seven turbines had rated power output of $2000 \mathrm{~kW}$. Technical specifications of these turbines are given in Tables $2-4$.

\subsection{Selection of Turbines between 500 and $750 \mathrm{~kW}$ Rated Output}

The results for the seven turbines mentioned in Table 2 are displayed in Tables A1-A7 in Appendix A. Columns 1-3 in each table enlist the first level decision criteria which are hub height, wind speed, and mean net energy output, respectively. These values were provided as input to the simulator. Columns 4-6 provide the individual membership values of the three decision criteria, respectively. The overall membership of the solution is thus found using Equation (4) by adding the individual deviations, and is given in the last column of each table. It is important to mention that, in Tables A1-A7, the measurements of hub height, and the corresponding wind speed and energy output, were taken based on the minimum hub height applicable to that turbine (i.e., as specified by the manufacturer). For example, the minimum hub height for Fuhrlder 600 is 50 m, for Vestas V47 
is $55 \mathrm{~m}$, and so on. Therefore, measurements were taken considering the minimum hub heights as the lower limit for each respective turbine. Similarly, the maximum hub height for all turbines was assumed to be $120 \mathrm{~m}$.

Tables A1-A7 indicate that for all turbines, the best (maximum) overall membership is associated with highest hub height of $120 \mathrm{~m}$, with the exception of Windflow 500 for which a hub height of $110 \mathrm{~m}$ produced the best solution. These results signify that the performance of turbines considering wind speed and energy output was better at higher hub heights than at lower hub heights.

The relative performance of the wind turbines was also assessed. Table 6 provides the best results for each turbine. These results have been reproduced from Tables A1-A7 for convenience. As observed from these tables, Unison U57 demonstrated the best performance among all turbines. It is due to the fact that Unison U57 achieved the best balance between the hub height, wind speed, and energy output, as indicated by highest overall membership value of 0.631 . The other possible alternatives of Unison U57 were Fuhrlder FL 600 and Hyosung HS50 with overall memberships of 0.544 and 0.538 , respectively. The worst performance was demonstrated by Windflow 500 , which had the lowest overall membership of just 0.378 .

Table 6. Comparison of turbines in 500-750 kW range. $\mathrm{HH}=\mathrm{Hub}$ height in $\mathrm{m}$, WS = wind speed in $\mathrm{m} / \mathrm{s}$, and $\mathrm{EO}=$ energy output in $\mathrm{kWh} /$ year, Mem HH = hub height membership, Mem WS = wind speed membership, Mem EO = energy output membership, and $\mathrm{OM}=$ overall membership.

\begin{tabular}{cccccccc}
\hline Turbine & HH & WS & EO & Mem HH & Mem WS & Mem EO & OM \\
\hline Fuhrlder FL 600 & 120 & 5.85 & $1,372,142$ & 0.000 & 0.925 & 0.707 & 0.544 \\
Hyosung HS50 & 120 & 5.85 & $1,339,670$ & 0.000 & 0.925 & 0.689 & 0.538 \\
RRB Energy PS 600 & 120 & 5.85 & $1,137,149$ & 0.000 & 0.925 & 0.576 & 0.500 \\
Suzlon S.52/600 & 120 & 5.85 & $1,212,688$ & 0.000 & 0.925 & 0.618 & 0.514 \\
Unison U57 & 120 & 5.85 & $1,843,128$ & 0.000 & 0.925 & 0.968 & 0.631 \\
Vestas V47 & 120 & 5.85 & $1,186,994$ & 0.000 & 0.925 & 0.604 & 0.510 \\
Windflow 500 & 110 & 5.70 & 410,844 & 0.111 & 0.850 & 0.173 & 0.378 \\
\hline
\end{tabular}

\subsection{Selection of Turbines between 1000 and $1250 \mathrm{~kW}$ Rated Output}

Tables A8-A13 in Appendix A provide the results for the six turbines in the range of 1000-1250 kW mentioned in Table 3. Again, Columns 1-3 in Tables A8-A13 provide the values of the first-level decision criteria, i.e., hub height, wind speed, and mean net energy output, respectively. In addition, as before, Columns 4-6 provide the individual memberships of the three decision criteria, respectively. The overall membership of the solution is obtained by using Equation (4). The overall membership is given in the last column of each table. Note that in Tables A8-A13, the measurements of hub height, and the corresponding wind speed and energy output were taken based on the minimum hub height applicable to that turbine.

Tables A8-A13 show some interesting trends. All best results were obtained with hub heights of $120 \mathrm{~m}$, corresponding to wind speed of $7.28 \mathrm{~m} / \mathrm{s}$. The above results clearly indicate that the performance of turbines considering wind speed and energy output was best at highest hub height considered in the measurements.

The relative performance of the wind turbines was also evaluated. Table 7 depicts the best results for each turbine. These results have been reproduced from Tables A8-A13 for the sake of completeness. As observed from Table 7, Vensys 62-1200 demonstrated the best performance among all turbines since it has the highest overall membership of 0.641 , followed by Suzlon S.62/1000 with an overall membership of 0.588 , and so on. The worst performance was shown by Nordex N54/1000, which had the lowest overall membership of 0.495 . 
Table 7. Comparison of turbines in 1000-1250 kW range. $\mathrm{HH}=\mathrm{Hub}$ height in $\mathrm{m}$, WS = wind speed in $\mathrm{m} / \mathrm{s}$, and $\mathrm{EO}=$ energy output in $\mathrm{kWh} /$ year, Mem HH = hub height membership, Mem WS = wind speed membership, Mem EO = energy output membership, and $\mathrm{OM}=$ overall membership.

\begin{tabular}{cccccccc}
\hline Turbine & HH & WS & EO & Mem HH & Mem WS & Mem EO & OM \\
\hline AAER A-1000 & 120 & 5.85 & $1,795,286$ & 0.000 & 0.925 & 0.762 & 0.562 \\
DeWind D6 64m & 120 & 5.85 & $1,615,199$ & 0.000 & 0.925 & 0.656 & 0.527 \\
Mitsubishi MWT62 & 120 & 5.85 & $1,868,132$ & 0.000 & 0.925 & 0.805 & 0.577 \\
Nordex N54/1000 & 120 & 5.85 & $1,453,262$ & 0.000 & 0.925 & 0.561 & 0.495 \\
Suzlon S.62/1000 & 120 & 5.85 & $1,924,100$ & 0.000 & 0.925 & 0.838 & 0.588 \\
Vensys 62-1200 & 120 & 5.85 & $2,198,506$ & 0.000 & 0.925 & 0.999 & 0.641 \\
\hline
\end{tabular}

\subsection{Selection of Turbines with $2000 \mathrm{~kW}$ Rated Output}

Turbines with rated output of $2000 \mathrm{~kW}$ were also evaluated. Tables A14-A20 in Appendix A provide the results for the seven turbines mentioned in Table 4 where all turbines were having the same rated power of $2000 \mathrm{~kW}$. Similar to previous sections, Columns 1-3 of each table enlist the three decision criteria of hub height, wind speed, and mean net energy output, respectively. In addition, as before, Columns 4-6 provide the individual memberships of the three decision criteria, respectively. The overall membership of the solution is obtained by using Equation (4) as given in the last column of each table. Similar to previous cases, the measurements of hub height, and the corresponding wind speed and energy output were taken based on the minimum hub height applicable to that turbine.

The results revealed by Tables A14-A20 are quite noteworthy. A pattern similar to what was observed in Section 6.2 is seen here as well. That is, all best performances were obtained at hub heights of $120 \mathrm{~m}$ where the wind speed was $7.28 \mathrm{~m} / \mathrm{s}$. With regard to the relative performance of each turbine, results in Table 8 indicate that REpower MM92 was the best performer as it resulted in the highest overall membership of 0.620 while DeWind D8.1 was worst in performance due its lowest overall membership deviation of 0.432 .

Table 8. Comparison of turbines with rated power of $2000 \mathrm{~kW}$. HH = Hub height in $\mathrm{m}, \mathrm{WS}=$ wind speed in $\mathrm{m} / \mathrm{s}$, and $\mathrm{EO}=$ energy output in $\mathrm{kWh} /$ year, Mem $\mathrm{HH}=$ hub height membership, Mem WS = wind speed membership, Mem EO = energy output membership, and $\mathrm{OM}=$ overall membership.

\begin{tabular}{cccccccc}
\hline Turbine & HH & WS & EO & Mem HH & Mem WS & Mem EO & OM \\
\hline AAER A-2000-84 & 120 & 5.85 & $3,881,328$ & 0.000 & 0.925 & 0.739 & 0.555 \\
DeWind D8.1 & 120 & 5.85 & $2,443,060$ & 0.000 & 0.925 & 0.370 & 0.432 \\
Ecotecnia 80/2000 & 120 & 5.85 & $3,244,719$ & 0.000 & 0.925 & 0.576 & 0.500 \\
REpower MM92 & 120 & 5.85 & $4,649,758$ & 0.000 & 0.925 & 0.936 & 0.620 \\
Suzlon S.88/2000 & 120 & 5.85 & $3,934,755$ & 0.000 & 0.925 & 0.753 & 0.559 \\
Unison U93 & 120 & 5.85 & $3,748,612$ & 0.000 & 0.925 & 0.705 & 0.543 \\
Vestas V90 & 120 & 5.85 & $4,142,236$ & 0.000 & 0.925 & 0.806 & 0.577 \\
\hline
\end{tabular}

\subsection{Overall Best Performance of a Wind Turbine}

The results in Sections 6.1-6.3 assess the best turbine in three different ranges, namely, 500-750 kW, $1000-1250 \mathrm{~kW}$, and 1000-2000 kW. However, the results do not classify the overall best turbine considering all turbines simultaneously. In order to make that decision, more information other than what has been presented and analyzed in Sections 6.1-6.3 is needed. That decision can be made with the factors presented in Tables $2-4$. These factors include rotor diameter, cut-in wind speed, and rated wind speed. These factors play an important role in selecting a suitable wind turbine for a particular location from economical energy yield and ease of installation and maintenance. For example, larger the rotor diameter, more swept area and hence more power is expected from the wind turbine. However, there is a limit of the rotor diameter beyond which it will not be operational. Furthermore, lesser cut-in and rated wind speeds of a wind turbine would produce more energy, resulting in higher yields at low 
windy sites. Again, the technical aspects of developing such wind turbine blades need more research and development work.

In order to make appropriate decision, again fuzzy logic has been employed here using the strategy presented in Section 5.3. This strategy incorporates the cumulative results from Tables 6-8 combined with the memberships of each aforementioned factor and implemented as discussed in Section 5.3.4. Table 9 displays the individual memberships for the three factors, i.e., rotor diameter, cut-in wind speed, rated wind speed, and rated power, combined with the overall memberships of Section 5. The resulting membership is calculated using Equation (8) and is referred to as the total membership (TM) in the last column of Table 9.

It is observed from Table 9 that the best turbine for the underlying site is Unison U93 with the highest TM of 0.791 . This turbine has a rated output of $2000 \mathrm{~kW}$. Two other turbines, namely, REpower MM92 and AAER A-2000-84, are also close in performance to Unison U93. Furthermore, Windflow 500 has the lowest TM of 0.239 , indicating that this is the worst turbine for the underlying wind farm site. The turbine is in the $500-750 \mathrm{~kW}$ turbine range. Another trend observed in this table is that, in general, turbines with rated power of $2000 \mathrm{~kW}$ are most suitable for the wind farm site of Qassim because all turbines have a higher TM, while most turbines in 500-750 kW have low TM, indicating their unsuitability, in general, for the site.

Table 9. $\mathrm{TM}$ for all turbines. $\mathrm{OM}=$ overall membership and $\mathrm{TM}=$ total membership.

\begin{tabular}{|c|c|c|c|c|c|c|c|c|}
\hline Turbine & $\begin{array}{l}\text { Diameter } \\
\text { (m) }\end{array}$ & $\begin{array}{l}\text { Cut-in Wind } \\
\text { Speed }(\mathrm{m} / \mathrm{s})\end{array}$ & $\begin{array}{l}\text { Rated Wind } \\
\text { Speed }(\mathrm{m} / \mathrm{s})\end{array}$ & $\begin{array}{l}\text { Membership } \\
\text { Diameter }\end{array}$ & $\begin{array}{l}\text { Membership } \\
\text { Cut-in Speed }\end{array}$ & $\begin{array}{l}\text { Membership } \\
\text { Rated Speed }\end{array}$ & OM & TM \\
\hline Unison U93 & 93 & 3 & 11 & 0.97 & 0.8 & 0.83 & 0.543 & 0.786 \\
\hline REpower MM92 & 92 & 3 & 12.5 & 0.95 & 0.8 & 0.58 & 0.620 & 0.739 \\
\hline AAER A-2000-84 & 84 & 3.25 & 12 & 0.83 & 0.75 & 0.67 & 0.555 & 0.701 \\
\hline Vensys $62-1200$ & 62 & 2.5 & 11.5 & 0.49 & 0.9 & 0.75 & 0.641 & 0.696 \\
\hline Vestas V90 & 90 & 4 & 12 & 0.92 & 0.6 & 0.67 & 0.577 & 0.692 \\
\hline Unison U57 & 57 & 3 & 10.5 & 0.42 & 0.8 & 0.92 & 0.631 & 0.691 \\
\hline Ecotecnia 80/2000 & 80 & 3 & 12 & 0.77 & 0.8 & 0.67 & 0.500 & 0.684 \\
\hline Fuhrlder FL 600 & 50 & 2.5 & 11 & 0.31 & 0.9 & 0.83 & 0.544 & 0.646 \\
\hline DeWind D6 64m & 64 & 2.5 & 12.3 & 0.52 & 0.9 & 0.62 & 0.527 & 0.642 \\
\hline Suzlon S.62/1000 & 62 & 3 & 12 & 0.49 & 0.8 & 0.67 & 0.588 & 0.637 \\
\hline DeWind D8.1 & 80 & 3 & 13.5 & 0.77 & 0.8 & 0.42 & 0.432 & 0.604 \\
\hline Suzlon S.88/2000 & 88 & 4 & 14 & 0.89 & 0.6 & 0.33 & 0.559 & 0.596 \\
\hline Hyosung HS50 & 50 & 3.5 & 11 & 0.31 & 0.7 & 0.83 & 0.538 & 0.595 \\
\hline Mitsubishi MWT62 & 61.4 & 3.5 & 12.5 & 0.48 & 0.7 & 0.58 & 0.577 & 0.586 \\
\hline AAER A-1000 & 58 & 4 & 12 & 0.43 & 0.6 & 0.67 & 0.562 & 0.565 \\
\hline Suzlon S.52/600 & 52 & 4 & 13 & 0.34 & 0.6 & 0.50 & 0.618 & 0.514 \\
\hline Vestas V47 & 47 & 4 & 13 & 0.26 & 0.6 & 0.50 & 0.510 & 0.468 \\
\hline Nordex N54/1000 & 54 & 3.75 & 14 & 0.37 & 0.65 & 0.33 & 0.495 & 0.462 \\
\hline RRB Energy PS 600 & 47 & 3.5 & 15 & 0.26 & 0.7 & 0.17 & 0.500 & 0.407 \\
\hline Windflow 500 & 33 & 6 & 14 & 0.05 & 0.2 & 0.33 & 0.378 & 0.239 \\
\hline
\end{tabular}

\section{Conclusions}

An efficient wind farm design primarily requires the deployment of appropriate turbines that suit the needs of the site. Selection of an appropriate wind turbine from many available alternatives is a difficult task and requires consideration of various factors in the decision-making process. Six key decision factors are hub height, wind speed, mean net energy output, rotor diameter, cut-in wind speed, and rated wind speed. This paper presented a fuzzy logic based two-level MCDM approach for the turbine selection problem. The proposed approach was applied to data collected from the potential site of Qassim, Saudi Arabia. The effectiveness of the approach was analyzed through application on various turbines with nominal power in the ranges of 500-750 kW, 1000-1250 kW, and $2000 \mathrm{~kW}$. According to the obtained results, Unison U 93 turned out to be the best turbine while Windflow 500 was the worst turbine.

Acknowledgments: This work was supported by Deanship of Research at King Fahd University of Petroleum \& Minerals, Saudi Arabia, under project number IN141039. The publication cost will be partially compensated through project budget upon publication of the paper. The remaining difference will be paid by the authors. 
Author Contributions: Shafiqur Rehman collected the data for the study and proposed the overall framework. He proposed the criteria for selection of turbines. He also performed part of the literature review and wrote Sections 1 and 2, and partially Section 3, as well as the Abstract. He also performed part of analysis of results. Salman A. Khan developed the fuzzy logic based two-level turbine selection strategy, including the development of fuzzy membership functions, and decision functions. He also analyzed the data and wrote Section 3 (partially), Sections 4-6, and the Appendix A.

Conflicts of Interest: The authors declare no conflict of interest.

\section{Appendix A}

Table A1. Results for Fuhrlder FL 600 (Fuhrlder, Haiger, Germany). Mem HH = membership for hub height, Mem WS = membership for wind speed, Mem EO = Membership for energy output, and $\mathrm{OM}=$ overall membership. Best $\mathrm{OM}$ which corresponds to the best solution(s) is in bold.

\begin{tabular}{ccccccc}
\hline $\begin{array}{c}\text { Hub Height } \\
(\mathbf{H H})(\mathbf{m})\end{array}$ & $\begin{array}{c}\text { Hub Height Wind } \\
\text { Speed (WS) } \mathbf{( m / \mathbf { s } )}\end{array}$ & $\begin{array}{c}\text { Mean Net Energy Output } \\
\mathbf{( E O )}(\mathbf{k W h} / \text { Year) }\end{array}$ & Mem HH & Mem WS & Mem EO & OM \\
\hline 50 & 4.51 & 652,928 & 0.778 & 0.255 & 0.307 & 0.447 \\
55 & 4.63 & 706,370 & 0.722 & 0.315 & 0.337 & 0.458 \\
60 & 4.74 & 762,434 & 0.667 & 0.370 & 0.368 & 0.468 \\
65 & 4.86 & 814,177 & 0.611 & 0.430 & 0.397 & 0.479 \\
70 & 4.97 & 868,204 & 0.556 & 0.485 & 0.427 & 0.489 \\
75 & 5.07 & 922,046 & 0.500 & 0.535 & 0.457 & 0.497 \\
80 & 5.14 & 970,760 & 0.444 & 0.570 & 0.484 & 0.499 \\
85 & 5.26 & $1,028,540$ & 0.389 & 0.630 & 0.516 & 0.512 \\
90 & 5.35 & $1,080,891$ & 0.333 & 0.675 & 0.545 & 0.518 \\
95 & 5.44 & $1,132,390$ & 0.278 & 0.720 & 0.574 & 0.524 \\
100 & 5.49 & $1,173,203$ & 0.222 & 0.745 & 0.596 & 0.521 \\
105 & 5.61 & $1,232,176$ & 0.167 & 0.805 & 0.629 & 0.534 \\
110 & 5.7 & $1,280,293$ & 0.111 & 0.850 & 0.656 & 0.539 \\
115 & 5.78 & $1,326,950$ & 0.056 & 0.890 & 0.682 & 0.542 \\
120 & 5.85 & $1,372,142$ & 0.000 & 0.925 & 0.707 & $\mathbf{0 . 5 4 4}$ \\
\hline
\end{tabular}

Table A2. Results for Hyosung HS50 (Hyosung Corporation, Seoul, Korea). Mem HH = membership for hub height, Mem WS = membership for wind speed, Mem EO = Membership for energy output, and $\mathrm{OM}=$ overall membership. Best $\mathrm{OM}$ which corresponds to the best solution(s) is in bold.

\begin{tabular}{ccccccc}
\hline $\begin{array}{c}\text { Hub Height } \\
\mathbf{( H H )}(\mathbf{m})\end{array}$ & $\begin{array}{c}\text { Hub Height Wind } \\
\text { Speed (WS) } \mathbf{( m / s )}\end{array}$ & $\begin{array}{c}\text { Mean Net Energy Output } \\
\text { (EO) } \mathbf{( k W h / Y e a r ) ~}\end{array}$ & Mem HH & Mem WS & Mem EO & OM \\
\hline 50 & 4.51 & 595,719 & 0.778 & 0.255 & 0.275 & 0.436 \\
55 & 4.63 & 649,148 & 0.722 & 0.315 & 0.305 & 0.447 \\
60 & 4.74 & 705,486 & 0.667 & 0.370 & 0.336 & 0.458 \\
65 & 4.86 & 757,288 & 0.611 & 0.430 & 0.365 & 0.469 \\
70 & 4.97 & 811,782 & 0.556 & 0.485 & 0.395 & 0.479 \\
75 & 5.07 & 866,352 & 0.500 & 0.535 & 0.426 & 0.487 \\
80 & 5.14 & 916,259 & 0.444 & 0.570 & 0.453 & 0.489 \\
85 & 5.26 & 975,136 & 0.389 & 0.630 & 0.486 & 0.502 \\
90 & 5.35 & $1,029,202$ & 0.333 & 0.675 & 0.516 & 0.508 \\
95 & 5.44 & $1,082,817$ & 0.278 & 0.720 & 0.546 & 0.515 \\
100 & 5.49 & $1,126,225$ & 0.222 & 0.745 & 0.570 & 0.512 \\
105 & 5.61 & $1,188,073$ & 0.167 & 0.805 & 0.604 & 0.525 \\
110 & 5.7 & $1,239,561$ & 0.111 & 0.850 & 0.633 & 0.531 \\
115 & 5.78 & $1,290,144$ & 0.056 & 0.890 & 0.661 & 0.536 \\
120 & 5.85 & $1,339,670$ & 0.000 & 0.925 & 0.689 & $\mathbf{0 . 5 3 3}$ \\
\hline
\end{tabular}


Table A3. Results for RRB Energy PS 600 (RRB Energy, New Delhi, India). Mem HH = membership for hub height, Mem WS = membership for wind speed, Mem EO = Membership for energy output, and $\mathrm{OM}=$ overall membership. Best $\mathrm{OM}$ which corresponds to the best solution(s) is in bold.

\begin{tabular}{ccccccc}
\hline $\begin{array}{c}\text { Hub Height } \\
(\mathbf{H H})(\mathbf{m})\end{array}$ & $\begin{array}{c}\text { Hub Height Wind } \\
\text { Speed (WS) } \mathbf{( m / \mathbf { s } )}\end{array}$ & $\begin{array}{c}\text { Mean Net Energy Output } \\
\mathbf{( E O )}(\mathbf{k W h} / \text { Year) }\end{array}$ & Mem HH & Mem WS & Mem EO & OM \\
\hline 50 & 4.51 & 542,702 & 0.778 & 0.255 & 0.246 & 0.426 \\
55 & 4.63 & 587,970 & 0.722 & 0.315 & 0.271 & 0.436 \\
60 & 4.74 & 635,029 & 0.667 & 0.370 & 0.297 & 0.445 \\
65 & 4.86 & 677,883 & 0.611 & 0.430 & 0.321 & 0.454 \\
70 & 4.97 & 722,385 & 0.556 & 0.485 & 0.346 & 0.462 \\
75 & 5.07 & 766,484 & 0.500 & 0.535 & 0.370 & 0.468 \\
80 & 5.14 & 806,222 & 0.444 & 0.570 & 0.392 & 0.469 \\
85 & 5.26 & 853,295 & 0.389 & 0.630 & 0.418 & 0.479 \\
90 & 5.35 & 896,000 & 0.333 & 0.675 & 0.442 & 0.484 \\
95 & 5.44 & 938,074 & 0.278 & 0.720 & 0.466 & 0.488 \\
100 & 5.49 & 971,518 & 0.222 & 0.745 & 0.484 & 0.484 \\
105 & 5.61 & $1,020,077$ & 0.167 & 0.805 & 0.511 & 0.494 \\
110 & 5.7 & $1,059,956$ & 0.111 & 0.850 & 0.533 & 0.498 \\
115 & 5.78 & $1,098,993$ & 0.056 & 0.890 & 0.555 & $\mathbf{0 . 5 0 0}$ \\
120 & 5.85 & $1,137,149$ & 0.000 & 0.925 & 0.576 & $\mathbf{0 . 5 0 0}$ \\
\hline
\end{tabular}

Table A4. Results for Suzlon S.52/600 (Suzlon, Ahmedabad, India). Mem HH = membership for hub height, Mem WS = membership for wind speed, Mem EO = Membership for energy output, and $\mathrm{OM}=$ overall membership. Best $\mathrm{OM}$ which corresponds to the best solution(s) is in bold.

\begin{tabular}{ccccccc}
\hline $\begin{array}{c}\text { Hub Height } \\
(\mathbf{H H})(\mathbf{m})\end{array}$ & $\begin{array}{c}\text { Hub Height Wind } \\
\text { Speed (WS) } \mathbf{( m / s )}\end{array}$ & $\begin{array}{c}\text { Mean Net Energy Output } \\
\text { (EO) } \mathbf{( k W h / Y e a r ) ~}\end{array}$ & Mem HH & Mem WS & Mem EO & OM \\
\hline 80 & 5.14 & 833,566 & 0.444 & 0.570 & 0.408 & 0.474 \\
85 & 5.26 & 888,092 & 0.389 & 0.630 & 0.438 & 0.486 \\
90 & 5.35 & 937,648 & 0.333 & 0.675 & 0.465 & 0.491 \\
95 & 5.44 & 986,305 & 0.278 & 0.720 & 0.492 & 0.497 \\
100 & 5.49 & $1,025,036$ & 0.222 & 0.745 & 0.514 & 0.494 \\
105 & 5.61 & $1,080,418$ & 0.167 & 0.805 & 0.545 & 0.505 \\
110 & 5.7 & $1,125,783$ & 0.111 & 0.850 & 0.570 & 0.510 \\
115 & 5.78 & $1,169,886$ & 0.056 & 0.890 & 0.594 & 0.513 \\
120 & 5.85 & $1,212,688$ & 0.000 & 0.925 & 0.618 & $\mathbf{0 . 5 1 4}$ \\
\hline
\end{tabular}

Table A5. Results for Unison U57 (Unison, Gyeongsangnam-Do, Korea). Mem HH = membership for hub height, Mem WS = membership for wind speed, Mem EO = Membership for energy output, and $\mathrm{OM}=$ overall membership. Best OM which corresponds to the best solution(s) is in bold.

\begin{tabular}{ccccccc}
\hline $\begin{array}{c}\text { Hub Height } \\
(\mathbf{H H})(\mathbf{m})\end{array}$ & $\begin{array}{c}\text { Hub Height Wind } \\
\text { Speed (WS) }(\mathbf{m} / \mathbf{s})\end{array}$ & $\begin{array}{c}\text { Mean Net Energy Output } \\
\text { (EO) } \mathbf{( k W h / Y e a r )}\end{array}$ & Mem HH & Mem WS & Mem EO & OM \\
\hline 70 & 4.97 & $1,197,179$ & 0.556 & 0.485 & 0.610 & 0.550 \\
75 & 5.07 & $1,266,399$ & 0.500 & 0.535 & 0.648 & 0.561 \\
80 & 5.14 & $1,328,827$ & 0.444 & 0.570 & 0.683 & 0.566 \\
85 & 5.26 & $1,403,430$ & 0.389 & 0.630 & 0.724 & 0.581 \\
90 & 5.35 & $1,470,875$ & 0.333 & 0.675 & 0.762 & 0.590 \\
95 & 5.44 & $1,537,157$ & 0.278 & 0.720 & 0.798 & 0.599 \\
100 & 5.49 & $1,589,262$ & 0.222 & 0.745 & 0.827 & 0.598 \\
105 & 5.61 & $1,665,206$ & 0.167 & 0.805 & 0.870 & 0.614 \\
110 & 5.7 & $1,726,494$ & 0.111 & 0.850 & 0.904 & 0.622 \\
115 & 5.78 & $1,785,919$ & 0.056 & 0.890 & 0.937 & 0.627 \\
120 & 5.85 & $1,843,128$ & 0.000 & 0.925 & 0.968 & $\mathbf{0 . 6 3 1}$ \\
\hline
\end{tabular}


Table A6. Results for Vestas V47 (Vestas, Smed Hansensvej, Denmark). Mem HH = membership for hub height, Mem WS = membership for wind speed, Mem EO = Membership for energy output, and $\mathrm{OM}=$ overall membership. Best $\mathrm{OM}$ which corresponds to the best solution(s) is in bold.

\begin{tabular}{|c|c|c|c|c|c|c|}
\hline $\begin{array}{l}\text { Hub Height } \\
\text { (HH) (m) }\end{array}$ & $\begin{array}{l}\text { Hub Height Wind } \\
\text { Speed (WS) }(\mathrm{m} / \mathrm{s})\end{array}$ & $\begin{array}{l}\text { Mean Net Energy Output } \\
\text { (EO) (kWh/Year) }\end{array}$ & Mem HH & Mem WS & Mem EO & OM \\
\hline 55 & 4.63 & 576,683 & 0.722 & 0.315 & 0.265 & 0.434 \\
\hline 60 & 4.74 & 627,796 & 0.667 & 0.370 & 0.293 & 0.443 \\
\hline 65 & 4.86 & 674,633 & 0.611 & 0.430 & 0.319 & 0.453 \\
\hline 70 & 4.97 & 723,647 & 0.556 & 0.485 & 0.346 & 0.462 \\
\hline 75 & 5.07 & 772,467 & 0.500 & 0.535 & 0.374 & 0.470 \\
\hline 80 & 5.14 & 816,847 & 0.444 & 0.570 & 0.398 & 0.471 \\
\hline 85 & 5.26 & 869,067 & 0.389 & 0.630 & 0.427 & 0.482 \\
\hline 90 & 5.35 & 916,763 & 0.333 & 0.675 & 0.454 & 0.487 \\
\hline 95 & 5.44 & 963,831 & 0.278 & 0.720 & 0.480 & 0.493 \\
\hline 100 & 5.49 & $1,001,605$ & 0.222 & 0.745 & 0.501 & 0.489 \\
\hline 105 & 5.61 & $1,055,687$ & 0.167 & 0.805 & 0.531 & 0.501 \\
\hline 110 & 5.7 & $1,100,406$ & 0.111 & 0.850 & 0.556 & 0.506 \\
\hline 115 & 5.78 & $1,144,187$ & 0.056 & 0.890 & 0.580 & 0.509 \\
\hline 120 & 5.85 & $1,186,994$ & 0.000 & 0.925 & 0.604 & 0.510 \\
\hline
\end{tabular}

Table A7. Results for Windflow 500 (Windflow Technology, Christchurch, Newzealand). Mem HH = membership for hub height, Mem WS = membership for wind speed, Mem EO = Membership for energy output, and $\mathrm{OM}=$ overall membership. Best $\mathrm{OM}$ which corresponds to the best solution(s) is in bold.

\begin{tabular}{|c|c|c|c|c|c|c|}
\hline $\begin{array}{l}\text { Hub Height } \\
\text { (HH) (m) }\end{array}$ & $\begin{array}{l}\text { Hub Height Wind } \\
\text { Speed (WS) }(\mathrm{m} / \mathrm{s})\end{array}$ & $\begin{array}{l}\text { Mean Net Energy Output } \\
\text { (EO) (kWh/Year) }\end{array}$ & Mem HH & Mem WS & Mem EO & OM \\
\hline 40 & 4.24 & 110,514 & 0.889 & 0.120 & 0.006 & 0.338 \\
\hline 45 & 4.38 & 126,293 & 0.833 & 0.190 & 0.015 & 0.346 \\
\hline 50 & 4.51 & 143,407 & 0.778 & 0.255 & 0.024 & 0.352 \\
\hline 55 & 4.63 & 161,749 & 0.722 & 0.315 & 0.034 & 0.357 \\
\hline 60 & 4.74 & 182,070 & 0.667 & 0.370 & 0.046 & 0.361 \\
\hline 65 & 4.86 & 201,577 & 0.611 & 0.430 & 0.056 & 0.366 \\
\hline 70 & 4.97 & 222,804 & 0.556 & 0.485 & 0.068 & 0.370 \\
\hline 75 & 5.07 & 244,719 & 0.500 & 0.535 & 0.080 & 0.372 \\
\hline 80 & 5.14 & 265,741 & 0.444 & 0.570 & 0.092 & 0.369 \\
\hline 85 & 5.26 & 290,323 & 0.389 & 0.630 & 0.106 & 0.375 \\
\hline 90 & 5.35 & 313,820 & 0.333 & 0.675 & 0.119 & 0.376 \\
\hline 95 & 5.44 & 337,672 & 0.278 & 0.720 & 0.132 & 0.377 \\
\hline 100 & 5.49 & 358,219 & 0.222 & 0.745 & 0.143 & 0.370 \\
\hline 105 & 5.61 & 386,236 & 0.167 & 0.805 & 0.159 & 0.377 \\
\hline 110 & 5.7 & 410,844 & 0.111 & 0.850 & 0.173 & 0.378 \\
\hline 115 & 5.78 & 435,602 & 0.056 & 0.890 & 0.186 & 0.377 \\
\hline 120 & 5.85 & 460,449 & 0.000 & 0.925 & 0.200 & 0.375 \\
\hline
\end{tabular}

Table A8. Results for AAER A-1000 (AAER, Fort Lee, NJ, USA). Mem HH = membership for hub height, Mem WS = membership for wind speed, Mem EO = Membership for energy output, and OM = overall membership. Best OM which corresponds to the best solution(s) is in bold.

\begin{tabular}{|c|c|c|c|c|c|c|}
\hline $\begin{array}{l}\text { Hub Height } \\
\text { (HH) (m) }\end{array}$ & $\begin{array}{l}\text { Hub Height Wind } \\
\text { Speed (WS) }(\mathrm{m} / \mathrm{s})\end{array}$ & $\begin{array}{l}\text { Mean Net Energy Output } \\
\text { (EO) (kWh/Year) }\end{array}$ & Mem HH & Mem WS & Mem EO & OM \\
\hline 70 & 4.97 & $1,092,548$ & 0.556 & 0.485 & 0.349 & 0.463 \\
\hline 75 & 5.07 & $1,164,244$ & 0.500 & 0.535 & 0.391 & 0.475 \\
\hline 80 & 5.14 & $1,229,889$ & 0.444 & 0.570 & 0.429 & 0.481 \\
\hline 85 & 5.26 & $1,307,623$ & 0.389 & 0.630 & 0.475 & 0.498 \\
\hline 90 & 5.35 & $1,379,165$ & 0.333 & 0.675 & 0.517 & 0.508 \\
\hline 95 & 5.44 & $1,450,104$ & 0.278 & 0.720 & 0.559 & 0.519 \\
\hline 100 & 5.49 & $1,507,924$ & 0.222 & 0.745 & 0.593 & 0.520 \\
\hline 105 & 5.61 & $1,590,646$ & 0.167 & 0.805 & 0.642 & 0.538 \\
\hline 110 & 5.7 & $1,659,849$ & 0.111 & 0.850 & 0.682 & 0.548 \\
\hline 115 & 5.78 & $1,728,115$ & 0.056 & 0.890 & 0.722 & 0.556 \\
\hline 120 & 5.85 & $1,795,286$ & 0.000 & 0.925 & 0.762 & 0.562 \\
\hline
\end{tabular}


Table A9. Results for DeWind D6 64m (DeWind Co., Irvin Texas, TX, USA). Mem HH = membership for hub height, Mem WS = membership for wind speed, Mem EO = Membership for energy output, and $\mathrm{OM}=$ overall membership. Best $\mathrm{OM}$ which corresponds to the best solution(s) is in bold.

\begin{tabular}{ccccccc}
\hline $\begin{array}{c}\text { Hub Height } \\
(\mathbf{H H})(\mathbf{m})\end{array}$ & $\begin{array}{c}\text { Hub Height Wind } \\
\text { Speed (WS) } \mathbf{( m / s )}\end{array}$ & $\begin{array}{c}\text { Mean Net Energy Output } \\
\text { (EO) } \mathbf{( k W h / Y e a r )}\end{array}$ & Mem HH & Mem WS & Mem EO & OM \\
\hline 60 & 4.74 & 768,321 & 0.667 & 0.370 & 0.158 & 0.398 \\
65 & 4.86 & 830,723 & 0.611 & 0.430 & 0.195 & 0.412 \\
70 & 4.97 & 897,357 & 0.556 & 0.485 & 0.234 & 0.425 \\
75 & 5.07 & 965,498 & 0.500 & 0.535 & 0.274 & 0.436 \\
80 & 5.14 & $1,029,615$ & 0.444 & 0.570 & 0.312 & 0.442 \\
85 & 5.26 & $1,105,671$ & 0.389 & 0.630 & 0.356 & 0.458 \\
90 & 5.35 & $1,177,202$ & 0.333 & 0.675 & 0.398 & 0.469 \\
95 & 5.44 & $1,249,489$ & 0.278 & 0.720 & 0.441 & 0.480 \\
100 & 5.49 & $1,310,444$ & 0.222 & 0.745 & 0.477 & 0.481 \\
105 & 5.61 & $1,395,408$ & 0.167 & 0.805 & 0.527 & 0.499 \\
110 & 5.7 & $1,468,714$ & 0.111 & 0.850 & 0.570 & 0.510 \\
115 & 5.78 & $1,542,060$ & 0.056 & 0.890 & 0.613 & 0.520 \\
120 & 5.85 & $1,615,199$ & 0.000 & 0.925 & 0.656 & $\mathbf{0 . 5 2 7}$ \\
\hline
\end{tabular}

Table A10. Results for Mitsubishi MWT62-1000 (Mitsubishi Heavy Industries, Ltd., Yokohama, Japan). Mem HH = membership for hub height, Mem WS = membership for wind speed, Mem EO = Membership for energy output, and $\mathrm{OM}=$ overall membership. Best $\mathrm{OM}$ which corresponds to the best solution(s) is in bold.

\begin{tabular}{ccccccc}
\hline $\begin{array}{c}\text { Hub Height } \\
\mathbf{( H H )}(\mathbf{m})\end{array}$ & $\begin{array}{c}\text { Hub Height Wind } \\
\text { Speed (WS) }(\mathbf{m} / \mathbf{s})\end{array}$ & $\begin{array}{c}\text { Mean Net Energy Output } \\
\mathbf{( E O )}(\mathbf{k W h} / \text { Year) }\end{array}$ & Mem HH & Mem WS & Mem EO & OM \\
\hline 70 & 4.97 & $1,107,203$ & 0.556 & 0.485 & 0.357 & 0.466 \\
75 & 5.07 & $1,186,578$ & 0.500 & 0.535 & 0.404 & 0.480 \\
80 & 5.14 & $1,259,280$ & 0.444 & 0.570 & 0.447 & 0.487 \\
85 & 5.26 & $1,344,546$ & 0.389 & 0.630 & 0.497 & 0.505 \\
90 & 5.35 & $1,422,785$ & 0.333 & 0.675 & 0.543 & 0.517 \\
95 & 5.44 & $1,500,184$ & 0.278 & 0.720 & 0.588 & 0.529 \\
100 & 5.49 & $1,562,804$ & 0.222 & 0.745 & 0.625 & 0.531 \\
105 & 5.61 & $1,651,587$ & 0.167 & 0.805 & 0.677 & 0.550 \\
110 & 5.7 & $1,725,379$ & 0.111 & 0.850 & 0.721 & 0.561 \\
115 & 5.78 & $1,797,630$ & 0.056 & 0.890 & 0.763 & 0.570 \\
120 & 5.85 & $1,868,132$ & 0.000 & 0.925 & 0.805 & $\mathbf{0 . 5 7 7}$ \\
\hline
\end{tabular}

Table A11. Results Nordex N54/1000 kW (Nordex SE, Hamburg, Germany). Mem HH = membership for hub height, Mem WS = membership for wind speed, Mem EO = Membership for energy output, and $\mathrm{OM}=$ overall membership. Best OM which corresponds to the best solution(s) is in bold.

\begin{tabular}{ccccccc}
\hline $\begin{array}{c}\text { Hub Height } \\
\mathbf{( H H )}(\mathbf{m})\end{array}$ & $\begin{array}{c}\text { Hub Height Wind } \\
\text { Speed (WS) }(\mathbf{m} / \mathbf{s})\end{array}$ & $\begin{array}{c}\text { Mean Net Energy Output } \\
\mathbf{( E O )}(\mathbf{k W h} / \text { Year) }\end{array}$ & Mem HH & Mem WS & Mem EO & OM \\
\hline 60 & 4.74 & 733,028 & 0.667 & 0.370 & 0.137 & 0.391 \\
65 & 4.86 & 789,610 & 0.611 & 0.430 & 0.170 & 0.404 \\
70 & 4.97 & 849,597 & 0.556 & 0.485 & 0.206 & 0.415 \\
75 & 5.07 & 910,199 & 0.500 & 0.535 & 0.241 & 0.425 \\
80 & 5.14 & 966,311 & 0.444 & 0.570 & 0.274 & 0.430 \\
85 & 5.26 & $1,032,431$ & 0.389 & 0.630 & 0.313 & 0.444 \\
90 & 5.35 & $1,093,755$ & 0.333 & 0.675 & 0.349 & 0.453 \\
95 & 5.44 & $1,154,895$ & 0.278 & 0.720 & 0.385 & 0.461 \\
100 & 5.49 & $1,205,141$ & 0.222 & 0.745 & 0.415 & 0.461 \\
105 & 5.61 & $1,275,903$ & 0.167 & 0.805 & 0.456 & 0.476 \\
110 & 5.7 & $1,335,783$ & 0.111 & 0.850 & 0.492 & 0.484 \\
115 & 5.78 & $1,394,937$ & 0.056 & 0.890 & 0.526 & 0.491 \\
120 & 5.85 & $1,453,262$ & 0.000 & 0.925 & 0.561 & $\mathbf{0 . 4 9 5}$ \\
\hline
\end{tabular}


Table A12. Results for Suzlon S.62/1000 (Suzlon, Ahmedabad, India). Mem HH = membership for hub height, Mem WS = membership for wind speed, Mem EO = Membership for energy output, and $\mathrm{OM}=$ overall membership. Best $\mathrm{OM}$ which corresponds to the best solution(s) is in bold.

\begin{tabular}{ccccccc}
\hline $\begin{array}{c}\text { Hub Height } \\
\mathbf{( H H )}(\mathbf{m})\end{array}$ & $\begin{array}{c}\text { Hub Height Wind } \\
\text { Speed (WS) } \mathbf{( m / s )}\end{array}$ & $\begin{array}{c}\text { Mean Net Energy Output } \\
\mathbf{( E O )}(\mathbf{k W h} / \text { Year) }\end{array}$ & Mem HH & Mem WS & Mem EO & OM \\
\hline 65 & 4.86 & $1,102,522$ & 0.611 & 0.430 & 0.354 & 0.465 \\
70 & 4.97 & $1,178,155$ & 0.556 & 0.485 & 0.399 & 0.480 \\
75 & 5.07 & $1,254,238$ & 0.500 & 0.535 & 0.444 & 0.493 \\
80 & 5.14 & $1,324,060$ & 0.444 & 0.570 & 0.485 & 0.500 \\
85 & 5.26 & $1,407,119$ & 0.389 & 0.630 & 0.534 & 0.517 \\
90 & 5.35 & $1,483,631$ & 0.333 & 0.675 & 0.579 & 0.529 \\
95 & 5.44 & $1,559,639$ & 0.278 & 0.720 & 0.623 & 0.540 \\
100 & 5.49 & $1,621,174$ & 0.222 & 0.745 & 0.660 & 0.542 \\
105 & 5.61 & $1,709,142$ & 0.167 & 0.805 & 0.711 & 0.561 \\
110 & 5.7 & $1,782,225$ & 0.111 & 0.850 & 0.754 & 0.572 \\
115 & 5.78 & $1,853,952$ & 0.056 & 0.890 & 0.796 & 0.581 \\
120 & 5.85 & $1,924,100$ & 0.000 & 0.925 & 0.838 & $\mathbf{0 . 5 8 8}$ \\
\hline
\end{tabular}

Table A13. Results for Vensys 62 (Vensys Energy, Nonnweiler, Germany). Mem HH = membership for hub height, Mem WS = membership for wind speed, Mem EO = Membership for energy output, and $\mathrm{OM}=$ overall membership. Best $\mathrm{OM}$ which corresponds to the best solution(s) is in bold.

\begin{tabular}{|c|c|c|c|c|c|c|}
\hline $\begin{array}{l}\text { Hub Height } \\
\text { (HH) (m) }\end{array}$ & $\begin{array}{l}\text { Hub Height Wind } \\
\text { Speed (WS) }(\mathrm{m} / \mathrm{s})\end{array}$ & $\begin{array}{l}\text { Mean Net Energy Output } \\
\text { (EO) (kWh/Year) }\end{array}$ & Mem HH & Mem WS & Mem EO & OM \\
\hline 70 & 4.97 & $1,373,601$ & 0.556 & 0.485 & 0.514 & 0.518 \\
\hline 80 & 5.14 & $1,535,143$ & 0.444 & 0.570 & 0.609 & 0.541 \\
\hline 85 & 5.26 & $1,626,994$ & 0.389 & 0.630 & 0.663 & 0.561 \\
\hline 90 & 5.35 & $1,711,099$ & 0.333 & 0.675 & 0.712 & 0.574 \\
\hline 100 & 5.49 & $1,862,038$ & 0.222 & 0.745 & 0.801 & 0.589 \\
\hline 105 & 5.61 & $1,959,121$ & 0.167 & 0.805 & 0.858 & 0.610 \\
\hline 110 & 5.7 & $2,040,071$ & 0.111 & 0.850 & 0.906 & 0.622 \\
\hline 115 & 5.78 & $2,119,946$ & 0.056 & 0.890 & 0.953 & 0.633 \\
\hline 120 & 5.85 & $2,198,506$ & 0.000 & 0.925 & 0.999 & 0.641 \\
\hline
\end{tabular}

Table A14. Results for AAER A-2000-84 (AAER, Fort Lee, NJ, USA). Mem HH = membership for hub height, Mem WS = membership for wind speed, Mem EO = Membership for energy output, and $\mathrm{OM}=$ overall membership. Best $\mathrm{OM}$ which corresponds to the best solution(s) is in bold.

\begin{tabular}{ccccccc}
\hline $\begin{array}{c}\text { Hub Height } \\
\mathbf{( H H )}(\mathbf{m})\end{array}$ & $\begin{array}{c}\text { Hub Height Wind } \\
\text { Speed (WS) }(\mathbf{m} / \mathbf{s})\end{array}$ & $\begin{array}{c}\text { Mean Net Energy Output } \\
\mathbf{( E O )}(\mathbf{k W h} / \text { Year) }\end{array}$ & Mem HH & Mem WS & Mem EO & OM \\
\hline 65 & 4.86 & $2,169,598$ & 0.611 & 0.430 & 0.300 & 0.447 \\
70 & 4.97 & $2,326,962$ & 0.556 & 0.485 & 0.340 & 0.460 \\
75 & 5.07 & $2,485,514$ & 0.500 & 0.535 & 0.381 & 0.472 \\
80 & 5.14 & $2,631,381$ & 0.444 & 0.570 & 0.418 & 0.478 \\
85 & 5.26 & $2,803,851$ & 0.389 & 0.630 & 0.463 & 0.494 \\
90 & 5.35 & $2,963,114$ & 0.333 & 0.675 & 0.503 & 0.504 \\
95 & 5.44 & $3,121,421$ & 0.278 & 0.720 & 0.544 & 0.514 \\
100 & 5.49 & $3,250,190$ & 0.222 & 0.745 & 0.577 & 0.515 \\
105 & 5.61 & $3,433,254$ & 0.167 & 0.805 & 0.624 & 0.532 \\
110 & 5.7 & $3,585,762$ & 0.111 & 0.850 & 0.663 & 0.541 \\
115 & 5.78 & $3,735,263$ & 0.056 & 0.890 & 0.701 & 0.549 \\
120 & 5.85 & $3,881,328$ & 0.000 & 0.925 & 0.739 & $\mathbf{0 . 5 5 5}$ \\
\hline
\end{tabular}


Table A15. Results for DeWind D8.1 (DeWind Co., Irvin Texas, TX, USA). Mem HH = membership for hub height, Mem WS = membership for wind speed, Mem EO = Membership for energy output, and $\mathrm{OM}=$ overall membership. Best $\mathrm{OM}$ which corresponds to the best solution(s) is in bold.

\begin{tabular}{ccccccc}
\hline $\begin{array}{c}\text { Hub Height } \\
(\mathbf{H H})(\mathbf{m})\end{array}$ & $\begin{array}{c}\text { Hub Height Wind } \\
\text { Speed (WS) }(\mathbf{m} / \mathbf{s})\end{array}$ & $\begin{array}{c}\text { Mean Net Energy Output } \\
\mathbf{( E O )}(\mathbf{k W h} / \text { Year) }\end{array}$ & Mem HH & Mem WS & Mem EO & OM \\
\hline 80 & 5.14 & $1,537,798$ & 0.444 & 0.570 & 0.138 & 0.384 \\
85 & 5.26 & $1,655,162$ & 0.389 & 0.630 & 0.168 & 0.396 \\
90 & 5.35 & $1,765,989$ & 0.333 & 0.675 & 0.196 & 0.402 \\
95 & 5.44 & $1,877,836$ & 0.278 & 0.720 & 0.225 & 0.408 \\
100 & 5.49 & $1,972,189$ & 0.222 & 0.745 & 0.249 & 0.406 \\
105 & 5.61 & $2,103,223$ & 0.167 & 0.805 & 0.283 & 0.418 \\
110 & 5.70 & $2,216,634$ & 0.111 & 0.850 & 0.312 & 0.424 \\
115 & 5.78 & $2,330,001$ & 0.056 & 0.890 & 0.341 & 0.429 \\
120 & 5.85 & $2,443,060$ & 0.000 & 0.925 & 0.370 & $\mathbf{0 . 4 3 2}$ \\
\hline
\end{tabular}

Table A16. Results for Ecotecnia 80/2000 (Alstom, Saint-Ouen, France). Mem HH = membership for hub height, Mem WS = membership for wind speed, Mem EO = Membership for energy output, and $\mathrm{OM}=$ overall membership. Best $\mathrm{OM}$ which corresponds to the best solution(s) is in bold.

\begin{tabular}{ccccccc}
\hline $\begin{array}{c}\text { Hub Height } \\
\mathbf{( H H )}(\mathbf{m})\end{array}$ & $\begin{array}{c}\text { Hub Height Wind } \\
\text { Speed (WS) }(\mathbf{m} / \mathbf{s})\end{array}$ & $\begin{array}{c}\text { Mean Net Energy Output } \\
\mathbf{( E O )}(\mathbf{k W h} / \text { Year) }\end{array}$ & Mem HH & Mem WS & Mem EO & OM \\
\hline 70 & 4.97 & $1,904,075$ & 0.556 & 0.485 & 0.232 & 0.424 \\
75 & 5.07 & $2,039,396$ & 0.500 & 0.535 & 0.267 & 0.434 \\
80 & 5.14 & $2,159,080$ & 0.444 & 0.570 & 0.297 & 0.437 \\
85 & 5.26 & $2,311,168$ & 0.389 & 0.630 & 0.336 & 0.452 \\
90 & 5.35 & $2,447,356$ & 0.333 & 0.675 & 0.371 & 0.460 \\
95 & 5.44 & $2,583,036$ & 0.278 & 0.720 & 0.406 & 0.468 \\
100 & 5.49 & $2,689,181$ & 0.222 & 0.745 & 0.433 & 0.467 \\
105 & 5.61 & $2,851,752$ & 0.167 & 0.805 & 0.475 & 0.482 \\
110 & 5.7 & $2,984,441$ & 0.111 & 0.850 & 0.509 & 0.490 \\
115 & 5.78 & $3,115,523$ & 0.056 & 0.890 & 0.542 & 0.496 \\
120 & 5.85 & $3,244,719$ & 0.000 & 0.925 & 0.576 & $\mathbf{0 . 5 0 0}$ \\
\hline
\end{tabular}

Table A17. Results for REpower MM92 (REpower, Tripsrath, Germany). Mem HH = membership for hub height, Mem WS = membership for wind speed, Mem EO = Membership for energy output, and $\mathrm{OM}=$ overall membership. Best $\mathrm{OM}$ which corresponds to the best solution(s) is in bold.

\begin{tabular}{ccccccc}
\hline $\begin{array}{c}\text { Hub Height } \\
(\mathbf{H H})(\mathbf{m})\end{array}$ & $\begin{array}{c}\text { Hub Height Wind } \\
\text { Speed (WS) }(\mathbf{m} / \mathbf{s})\end{array}$ & $\begin{array}{c}\text { Mean Net Energy Output } \\
\mathbf{( E O )}(\mathbf{k W h} / \text { Year) }\end{array}$ & Mem HH & Mem WS & Mem EO & OM \\
\hline 80 & 5.14 & $3,336,809$ & 0.444 & 0.570 & 0.599 & 0.538 \\
85 & 5.26 & $3,528,408$ & 0.389 & 0.630 & 0.648 & 0.556 \\
90 & 5.35 & $3,700,502$ & 0.333 & 0.675 & 0.692 & 0.567 \\
95 & 5.44 & $3,868,852$ & 0.278 & 0.720 & 0.736 & 0.578 \\
100 & 5.49 & $4,001,539$ & 0.222 & 0.745 & 0.770 & 0.579 \\
105 & 5.61 & $4,194,667$ & 0.167 & 0.805 & 0.819 & 0.597 \\
110 & 5.7 & $4,351,165$ & 0.111 & 0.850 & 0.859 & 0.607 \\
115 & 5.78 & $4,502,963$ & 0.056 & 0.890 & 0.898 & 0.615 \\
120 & 5.85 & $4,649,758$ & 0.000 & 0.925 & 0.936 & $\mathbf{0 . 6 2 0}$ \\
\hline
\end{tabular}


Table A18. Results for Suzlon S.88/2000 (Suzlon, Ahmedabad, India). Mem HH = membership for hub height, Mem WS = membership for wind speed, Mem EO = Membership for energy output, and $\mathrm{OM}=$ overall membership. Best $\mathrm{OM}$ which corresponds to the best solution(s) is in bold.

\begin{tabular}{ccccccc}
\hline $\begin{array}{c}\text { Hub Height } \\
(\mathbf{H H})(\mathbf{m})\end{array}$ & $\begin{array}{c}\text { Hub Height Wind } \\
\text { Speed (WS) }(\mathbf{m} / \mathbf{s})\end{array}$ & $\begin{array}{c}\text { Mean Net Energy Output } \\
\mathbf{( E O )}(\mathbf{k W h} / \text { Year) }\end{array}$ & Mem HH & Mem WS & Mem EO & OM \\
\hline 80 & 5.14 & $2,669,926$ & 0.444 & 0.570 & 0.428 & 0.481 \\
85 & 5.26 & $2,846,288$ & 0.389 & 0.630 & 0.473 & 0.497 \\
90 & 5.35 & $3,008,305$ & 0.333 & 0.675 & 0.515 & 0.508 \\
95 & 5.44 & $3,168,669$ & 0.278 & 0.720 & 0.556 & 0.518 \\
100 & 5.49 & $3,298,395$ & 0.222 & 0.745 & 0.589 & 0.519 \\
105 & 5.61 & $3,483,031$ & 0.167 & 0.805 & 0.637 & 0.536 \\
110 & 5.7 & $3,636,630$ & 0.111 & 0.850 & 0.676 & 0.546 \\
115 & 5.78 & $3,787,344$ & 0.056 & 0.890 & 0.715 & 0.553 \\
120 & 5.85 & $3,934,755$ & 0.000 & 0.925 & 0.753 & $\mathbf{0 . 5 5 9}$ \\
\hline
\end{tabular}

Table A19. Results for Unison U93 (Unison, Gyeongsangnam-Do, Korea). Mem HH = membership for hub height, Mem WS = membership for wind speed, Mem EO = Membership for energy output, and $\mathrm{OM}=$ overall membership. Best $\mathrm{OM}$ which corresponds to the best solution(s) is in bold.

\begin{tabular}{ccccccc}
\hline $\begin{array}{c}\text { Hub Height } \\
(\mathbf{H H})(\mathbf{m})\end{array}$ & $\begin{array}{c}\text { Hub Height Wind } \\
\text { Speed (WS) }(\mathbf{m} / \mathbf{s})\end{array}$ & $\begin{array}{c}\text { Mean Net Energy Output } \\
\text { (EO) } \mathbf{( k W h / Y e a r )}\end{array}$ & Mem HH & Mem WS & Mem EO & OM \\
\hline 80 & 5.14 & $2,483,854$ & 0.444 & 0.570 & 0.380 & 0.465 \\
85 & 5.26 & $2,657,287$ & 0.389 & 0.630 & 0.425 & 0.481 \\
90 & 5.35 & $2,817,926$ & 0.333 & 0.675 & 0.466 & 0.491 \\
95 & 5.44 & $2,978,000$ & 0.278 & 0.720 & 0.507 & 0.502 \\
100 & 5.49 & $3,109,319$ & 0.222 & 0.745 & 0.541 & 0.503 \\
105 & 5.61 & $3,293,851$ & 0.167 & 0.805 & 0.588 & 0.520 \\
110 & 5.7 & $3,448,573$ & 0.111 & 0.850 & 0.628 & 0.530 \\
115 & 5.78 & $3,600,356$ & 0.056 & 0.890 & 0.667 & 0.537 \\
120 & 5.85 & $3,748,612$ & 0.000 & 0.925 & 0.705 & $\mathbf{0 . 5 4 3}$ \\
\hline
\end{tabular}

Table A20. Results for Vestas V90 (Vestas, Smed Hansensvej, Denmark). Mem HH = membership for hub height, Mem WS = membership for wind speed, Mem EO = Membership for energy output, and $\mathrm{OM}=$ overall membership. Best $\mathrm{OM}$ which corresponds to the best solution(s) is in bold.

\begin{tabular}{ccccccc}
\hline $\begin{array}{c}\text { Hub Height } \\
(\mathbf{H H})(\mathbf{m})\end{array}$ & $\begin{array}{c}\text { Hub Height Wind } \\
\text { Speed (WS) }(\mathbf{m} / \mathbf{s})\end{array}$ & $\begin{array}{c}\text { Mean Net Energy Output } \\
\text { (EO) (kWh/Year) }\end{array}$ & Mem HH & Mem WS & Mem EO & OM \\
\hline 80 & 5.14 & $2,860,836$ & 0.444 & 0.570 & 0.477 & 0.497 \\
85 & 5.26 & $3,042,369$ & 0.389 & 0.630 & 0.524 & 0.514 \\
90 & 5.35 & $3,208,220$ & 0.333 & 0.675 & 0.566 & 0.525 \\
95 & 5.44 & $3,371,863$ & 0.278 & 0.720 & 0.608 & 0.535 \\
100 & 5.49 & $3,503,124$ & 0.222 & 0.745 & 0.642 & 0.536 \\
105 & 5.61 & $3,690,773$ & 0.167 & 0.805 & 0.690 & 0.554 \\
110 & 5.7 & $3,845,304$ & 0.111 & 0.850 & 0.730 & 0.564 \\
115 & 5.78 & $3,995,923$ & 0.056 & 0.890 & 0.768 & 0.571 \\
120 & 5.85 & $4,142,236$ & 0.000 & 0.925 & 0.806 & $\mathbf{0 . 5 7 7}$ \\
\hline
\end{tabular}

\section{References}

1. Rehman, S.; Baseer, M.; Meyer, J.; Alam, M.; Alhems, M.; Lashin, A.; AlArifi, N. Suitability of utilizing small horizontal axis wind turbines for off grid loads in Eastern Region of Saudi Arabia. Energy Explor. Exploit. 2016, 34, 449-467. [CrossRef]

2. Baseer, M.; Meyer, J.; Rehman, S.; Alam, M.; Al-Hadhrami, L.; Lashin, A. Performance evaluation of cup-anemometers and wind speed characteristics analysis. Renew. Energy 2016, 86, 733-744. [CrossRef]

3. Baseer, M.; Meyer, J.; Alam, M.; Rehman, S. Wind speed and power characteristics for Jubail industrial city, Saudi Arabia. Renew. Sustain. Energy Rev. 2015, 52, 1193-1204. [CrossRef] 
4. Khan, S. An automated decision-making approach for assortment of wind turbines-A case study of turbines in the range of $500 \mathrm{~kW}$ to $750 \mathrm{~kW}$. Int. J. Comput. Netw. Technol. 2015, 3, 75-81.

5. Rehman, S.; Al-Abbadi, N. Wind power characteristics on the north west coast of Saudi Arabia. Energy Environ. 2009, 20, 1257-1270. [CrossRef]

6. Global Wind Statistics. GWEC 2015. Available online: http://www.gwec.net/wp-content/uploads/vip/ GWEC-PRstats-2015_LR_corrected.pdf (accessed on 2 May 2016).

7. Khan, S.; Rehman, S. On the use of unified and-or fuzzy aggregation operator for multi-criteria decision making in wind farm design process using wind turbines in $500 \mathrm{~kW}-750 \mathrm{~kW}$ range. In Proceedings of the IEEE International Conference on Fuzzy Systems, Jeju Island, Korea, 20-24 August 2012.

8. Khan, S.; Rehman, S. On the use of Werners fuzzy aggregation operator for multi-criteria decision making in wind farm design process using wind turbines in $1000 \mathrm{~kW}-1200 \mathrm{~kW}$ range. In Proceedings of the International Clean Energy Conference, Lleida, Spain, 16-18 May 2012; pp. 163-170.

9. Khan, S.; Engelbrecht, A. A new fuzzy operator and its application to topology design of distributed local area networks. Inform. Sci. 2007, 177, 2692-2711. [CrossRef]

10. Werners, B. Aggregation models in mathematical programming. In Mathematical Models for Decision Support; Mittra, G., Greenberg, H., Lootsma, F., Rijckaert, M., Zimmerman, H., Eds.; Springer: Berlin/Heidelberg, Germany, 1988; Volume 48, pp. 295-305.

11. Dombi, J. A general class of fuzzy operators: The De Morgan class of fuzzy operators and fuzziness measures induced by fuzzy operators. Fuzzy Sets Syst. 1982, 8, 149-163. [CrossRef]

12. Dombi, J. Basic concepts for a theory of evaluation: The aggregative operator. Eur. J. Oper. Res. 1982, 10, 282-293. [CrossRef]

13. Hamacher, H. Ueber logische verknupfungen unschalfer aussagen und deren zugehoerige bewertungs-funktione. Prog. Cybern. Syst. Res. 1978, 3, 276-288.

14. Frank, M. On the simultaneous associativity of $\mathrm{F}(\mathrm{x} ; \mathrm{y})$ and $\mathrm{x}+\mathrm{y}-\mathrm{F}(\mathrm{x} ; \mathrm{y})$. Aequ. Math. 1979, 19, $194-226$. [CrossRef]

15. Weber, S. A general concept of fuzzy connectives, negations and implications based on t-norms and $\mathrm{t}$-conorms Fuzzy Sets Syst. 1983, 11, 115-134. [CrossRef]

16. Dubois, D.; Prade, S. A class of fuzzy measures based on triangular norms. Int. J. Gen. Syst. 1982, 8, $105-116$. [CrossRef]

17. Schweizer, B.; Sklar, A. Associative functions and abstracts semigroups. Publ. Math. 1963, 10, 69-81.

18. Gao, L. The fuzzy arithmetic mean operator. Fuzzy Sets Syst. 1999, 107, 335-348. [CrossRef]

19. Herbert-Acero, J.; Probst, O.; Réthoré, P.; Larsen, G.; Castillo-Villar, K.K. A review of methodological approaches for the design and optimization of wind farms. Energies 2014, 7, 6930-7016. [CrossRef]

20. Khan, S.; Rehman, S. Computational intelligence techniques for placement of wind turbines: A brief plan of research in Saudi Arabian perspective. In Proceedings of the IEEE International Energy Conference, Manama, Bahrain, 18-22 December 2010.

21. Khan, S.; Rehman, S. Iterative non-deterministic algorithms in on-shore wind farm design: A brief survey. Renew. Sustain. Energy Rev. 2013, 19, 370-384. [CrossRef]

22. Gass, S.; Saaty, T. The computational algorithm for the parametric objective Function. Nav. Res. Logist. Q. 1955, 2, 39-45. [CrossRef]

23. Goldberg, D. Genetic Algorithms in Search, Optimization, and Machine Learning; Addison Wesley: Reading, MA, USA, 1989.

24. Zadeh, L. The concept of a linguistic variable and its application to approximate reasoning. Inform. Sci. 1975, 8, 199-249. [CrossRef]

25. Szurek, M.; Blachowski, J.; Nowacka, A. GIS-based methods for wind farm location multi-criteria analysis. Min. Sci. 2014, 21, 65-81.

26. Höfer, T.; Sunak, Y.; Siddique, H.; Madlener, R. Wind Farm Siting Using a Spatial Analytic Hierarchy Process Approach: A Case Study of the Städteregion Aachen; FCN Working Paper No. 16; RWTH Aachen University: Aachen, Germany, 2014; Volume 2014, pp. 1-52.

27. Neufville, L. Wind Farm Site Suitability Selection Using Multi-Criteria Analysis and Spatial Modelling; Technical Report; University of Technology: Kingston, Jamaica, 2013.

28. Lee, A.; Chen, H.; Kang, H. Multi-criteria decision making on strategic selection of wind farms. Renew. Energy 2009, 34, 120-126. [CrossRef] 
29. Talinli, I.; Topuz, E.; Aydin, E.; Kabakci, S. A holistic approach for wind farm site selection by FAHP. In Wind Farm-Technical Regulations, Potential Estimation and Siting Assessment; Suvire, G., Ed.; InTech Publishers: New York, NY, USA, 2014; pp. 213-234.

30. Cavallaro, F.; Ciraolo, L. A multi-criteria approach to evaluate wind energy plants on an Italian island. Energy Policy 2005, 33, 235-244. [CrossRef]

31. Al-Yahyai, S.; Charabi, Y.; Gastlia, A.; Al-Badi, A. Wind farm land suitability indexing using multi-criteria analysis. Renew. Energy 2012, 44, 80-87. [CrossRef]

32. Hwang, G.; Wei, L.; Ching, K.; Lin, N. Wind farm allocation in Malaysia based on multi-criteria decision making method. In Proceedings of the IEEE National Postgraduate Conference, Perak, Malaysia, 19-20 September 2011.

33. Miller, A.; Li, R. A geospatial approach for prioritizing wind farm development in Northeast Nebraska, USA. ISPRS Int. J. Geo-Inform. 2014, 3, 968-979. [CrossRef]

34. Mosetti, G.; Poloni, C.; Diviacco, B. Optimization of wind turbine positioning in large wind farms by means of a genetic algorithm. J. Wind Eng. Ind. Aerodyn. 1994, 51, 105-116. [CrossRef]

35. Emami, A.; Noghreh, P. New approach on optimization in placement of wind turbines within wind farm by genetic algorithms. Renew. Energy 2010, 25, 1559-1564. [CrossRef]

36. Veeramachaneni, K.; Wagner, M.; O’Reilly, U.; Neumann, F. Optimizing energy output and layout costs for large wind farms using particle swarm optimization. In Proceedings of the IEEE Congress on Evolutionary Computation, Brisbane, Australia, 10-15 June 2012; pp. 1-7.

37. Heidarzade, F.; Varzandeh, M.; Rahbari, O.; Zavadskas, E.; Vafaeipour, M. Placement of wind farms based on a hybrid multi criteria decision making for Iran. In Proceedings of the 4th World Sustainability Forum, 1-30 November 2014.

38. Sisbot, S.; Turgut, O.; Tunc, M.; Camdali, U. Optimal positioning of wind turbines on Gokceada using multi-objective genetic algorithm. Wind Energy 2009, 13, 297-306. [CrossRef]

39. Kusiak, A.; Song, Z. Design of wind farm layout for maximum wind energy capture. Renew. Energy 2010, 35, 685-694. [CrossRef]

40. Kwong, W.Y.; Zhang, P.Y.; Romero, D.; Moran, J.; Morgenroth, M.; Amon, C. Wind farm layout optimization considering energy generation and noise propagation. In Proceedings of the ASME 2012 International Design Engineering Technology Conference and Computers and Information in Engineering Conference, Chicago, IL, USA, 12-15 August 2012; pp. 323-332.

41. Tran, R.; Wu, J.; Denison, C.; Ackling, T.; Wagner, M.; Neumann, F. Fast and effective multi-objective optimisation of wind turbine placement. In Proceedings of the 15th Conference on Genetic and Evolutionary Computation, Amsterdam, The Netherlands, 6-10 July 2013; pp. 1381-1388.

42. Kwong, W.Y.; Zhang, P.Y.; Romero, D.; Moran, J.; Morgenroth, M.; Amon, C. Multi-objective wind farm layout optimization considering energy generation and noise propagation with NSGA-II. J. Mech. Des. 2014, 136, 091010. [CrossRef]

43. Gonzalez, J.; Payan, M.; Santos, J.; Longatt, F. A review and recent develpments in the optimal wind turbine micro-siting problem. Renew. Sustain. Energy Rev. 2014, 30, 133-144. [CrossRef]

44. Taha, R.; Daim, T. Multi-criteria applications in renewable energy analysis, a literature review. In Research and Technology Management in the Electricity Industry, Green Energy and Technology; Daim, T., Oliver, T., Kim, J., Eds.; Springer: London, UK, 2013; pp. 17-30.

45. Sarja, J.; Halonen, V. Wind turbine selection criteria: A customer perspective. J. Energy Power Eng. 2013, 7, 1795-1802.

46. Perkin, S.; Garrett, D.; Jensson, P. Optimal wind turbine selection methodology: A case-study for Búrfell, Iceland. Renew. Energy 2015, 75, 165-172. [CrossRef]

47. Nemes, C.; Munteanu, F. Optimal selection of wind turbine for a specific area. In Proceedings of the IEEE 12th International Conference on Optimization of Electrical and Electronic Equipment, Brasov, Romania, 20-22 May 2010; pp. 1224-1229.

48. Chowdhury, S.; Zhang, J.; Messac, A.; Castillo, L. Optimizing the arrangement and the selection of turbines for wind farms subject to varying wind conditions. Renew. Energy 2013, 52, 273-282. [CrossRef]

49. Fotuhi-Firuzabad, M.; Dobakhshari, A.S. Reliability-based selection of wind turbines for large-scale wind Farms. World Acad. Sci. Eng. Technol. 2009, 49, 734-740. 
50. Bencherif, M.; Brahmi, B.; Chikhaoui, A. Optimum selection of wind turbines. Sci. J. Energy Eng. 2014, 2, 36-46. [CrossRef]

51. Montoya, F.; Manzano-Agugliaro, F.; López-Márquez, S.; Hernández-Escobedo, Q.; Gil, C. Wind turbine selection for wind farm layout using multi-objective evolutionary algorithms. Expert Syst. Appl. 2014, 41, 6585-6595. [CrossRef]

52. Chowdhury, S.; Mehmani, A.; Zhang, J.; Messac, A. Market suitability and performance tradeoffs offered by commercial wind turbines across differing wind regimes. Energies 2016, 9, 352. [CrossRef]

53. Martin, K.; Schmidt, M.; Shelton, S.; Stewart, S. Site specific optimization of rotor/generator sizing of wind turbines. Am. Soc. Mech. Eng. 2007, 1123-1130.

54. Bekele, A.; Ramayya, A. Site specific design optimization of horizontal axis wind turbine based on minimum cost of energy for Adama I wind farm. Int. J. Eng. Res. Technol. 2013, 2, 862-870.

55. Helgason, K. Selecting Optimum Location and Type of Wind Turbines in Iceland. Master's Thesis, Reykjavík University, Reykjavík, Iceland, 2012.

56. Eke, G.; Onyewudiala, J. Optimization of wind turbine blades using genetic algorithm. Glob. J. Res. Eng. 2012, 10, 22-26.

57. Jureczko, M.; Pawlak, M.; Mezyk, A. Optimisation of wind turbine blades. J. Mater. Process. Technol. 2005, 167, 463-471. [CrossRef]

58. Jowder, F.A.L. Wind power analysis and site matching of wind turbine generators in Kingdom of Bahrain. Appl. Energy 2009, 86, 538-545. [CrossRef]

59. El-Shimy, M. Optimal site matching of wind turbine generator: Case study of the Gulf of Suez region in Egypt. Renew. Energy 2010, 35, 1870-1878. [CrossRef]

60. Abul'Wafa, A.R. Matching wind turbine generators with wind regime in Egypt. Electr. Power Syst. Res. 2011, 81, 894-898. [CrossRef]

61. Dong, Y.; Wang, J.; Jiang, H.; Shi, X. Intelligent optimized wind resource assessment and wind turbines selection in Huitengxile of Inner Mongolia, China. Appl. Energy 2013, 109, 239-253. [CrossRef]

62. Shirgholami, Z.; Zangeneh, S.N.; Bortolini, M. Decision system to support the practitioners in the wind farm design: A case study for Iran mainland. Sustain. Energy Technol. Assess. 2016, 16, 1-10. [CrossRef]

63. Bagočius, V.; Zavadskas, E.; Turskis, Z. Multi-person selection of the best wind turbine based on the multi-criteria integrated additive multiplicative utility function. J. Civ. Eng. Manag. 2014, 20, 590-599. [CrossRef]

64. Lee, A.; Hung, M.; Kang, H.; Pearn, W. A wind turbine evaluation model under a multi-criteria decision making environment. Energy Convers. Manag. 2012, 64, 289-300. [CrossRef]

65. Marks, L.; Dunn, E.; Keller, J.; Godsey, L. Multiple criteria decision making (MCDM) using fuzzy logic: An innovative approach to sustainable agriculture. In Proceedings of the IEEE 3rd International Symposium on Uncertainty Modeling and Analysis and Annual Conference of the North American Fuzzy Information Processing Society, Los Alamitos, CA, USA, 17-20 September 1995; pp. 503-508.

66. Barin, A.; Canha, L.; Magnago, K. Multicriteria decision making for management of storage energy technologies on renewable hybrid systems-The analytic hierarchy process and the fuzzy logic. In Proceedings of the 6th International Conference on the European Energy Market, EEM 2009, Leuven, Belgium, 27-29 May 2009. [CrossRef]

67. Khan, S.; Baig, Z. On the use of unified And-Or fuzzy operator for distributed node exhaustion attack decision-making in wireless sensor networks. In Proceedings of the IEEE International Conference on Fuzzy Systems, Barcelona, Spain, 18-23 July 2010.

68. Ruan, D.; Lu, J.; Laes, E.; Zhang, G.; Wu, F.; Hardeman, F. Fuzzy multi-criteria group decision support in long-term options of Belgian energy policy. In Proceedings of the IEEE Annual Meeting of the North American Fuzzy Information Processing Society, San Diego, CA, USA, 24-27 June 2007; pp. 496-501.

69. Zimmermann, H.; Sebastian, H. Intelligent system design support by fuzzy-multi-criteria decision making and/or evolutionary algorithms. In Proceedings of the IEEE International Conference on Fuzzy Systems, Yokohama, Japan, 20-24 March 1995; pp. 367-374.

70. Lin, C. New product portfolio selection using fuzzy logic. In Proceedings of the IEEE International Conference on Industrial Engineering Management, Singapore, 2-4 December 2007; pp. 114-118.

71. Abdelbarr, M.; Khan, S. Design and analysis of a fault tolerant hybrid mobile scheme. Inform. Sci. 2007, 177, 2602-2620. [CrossRef] 
72. Khan, S.; Abdelbarr, M. On the use of fuzzy logic in a hybrid scheme for tolerating mobile support station failure. In Proceedings of the IEEE International Conference on Fuzzy Systems, Honolulu, HI, USA, 12-17 May 2002; pp. 717-722.

73. Sedki, K.; Delcroix, V. A hybrid approach for multi-criteria decision problems. In Proceedings of the IEEE Annual Meeting of the North American Fuzzy Information Processing Society, Toronto, ON, Canada, 12-14 July 2010; pp. 1-6.

74. Moaven, S.; Habibi, J.; Ahmadi, H.; Kamandi, A. A fuzzy model for solving architecture styles selection multi-criteria problem. In Proceedings of the Second UKSIM European Symposium on Computer Modeling and Simulation, Liverpool, UK, 8-10 September 2008; pp. 388-393.

75. Shragowitz, E.; Lee, J.; Kang, E. Application of fuzzy logic in computer-aided VLSI design. IEEE Trans. Fuzzy Syst. 1998, 6, 163-172. [CrossRef]

76. Hannan, E. On Fuzzy Goal Programming. Decis. Sci. 1981, 12, 522-531. [CrossRef]

(C) 2016 by the authors; licensee MDPI, Basel, Switzerland. This article is an open access article distributed under the terms and conditions of the Creative Commons Attribution (CC-BY) license (http://creativecommons.org/licenses/by/4.0/). 